\title{
Local and Remote Forcing Effects of Oceanic Eddies in the Subtropical Front Zone on the Mid- latitude Atmosphere in Winter
}

Haibo Hu ( $\sim$ huhaibo@nju.edu.cn )

Nanjing University https://orcid.org/0000-0003-1457-9538

Zhao Yihang

Nanjing University

Ning Zhang

Nanjing University

Haokun Bai

Nanjing University

\section{Feifei Chen}

Nanjing University

\section{Research Article}

Keywords: STFZ, oceanic eddies, remote forcing of eddies, atmospheric baroclinic waves, local forcing of eddies, MABL

Posted Date: April 1st, 2021

DOl: https://doi.org/10.21203/rs.3.rs-354498/v1

License: (c) (1) This work is licensed under a Creative Commons Attribution 4.0 International License. Read Full License

Version of Record: A version of this preprint was published at Climate Dynamics on July 8th, 2021. See the published version at https://doi.org/10.1007/s00382-021-05877-8. 


\title{
Local and Remote Forcing Effects of Oceanic Eddies in the Subtropical Front Zone on the Mid-latitude Atmosphere in Winter
}

\author{
Haibo Hü ${ }^{\#, *, 2}$, Zhao Yihang*, Ning Zhang*, Haokun Bai", Feifei Chen ${ }^{*}$ \\ * CMA-NJU Joint Laboratory for Climate Prediction Studies, Instituted for Climate and Global \\ Change Research, School of Atmospheric Science, Nanjing University, Nanjing 210093, China
}

${ }^{2}$ Key Laboratory of Meteorological Disaster of Ministry of Education, Nanjing University of Information Science and Technology, Nanjing 210044, China

\#Corresponding author: H.-B. Hu (huhaibo@nju.edu.cn)

\section{Declarations}

\section{Funding}

This work was supported by the National Key Program for Developing Basic Science (grants 2016YFA0600303 and 2018YFC1505900).

\section{Conflicts of interest/Competing interests}

The authors have no conflicts of interest to declare that are relevant to the content of this article.

Authors' contributions

Writing - original draft: Yihang Zhao and Haibo Hu

Writing - Review and Editing: Haibo Hu and Yihang Zhao

Visualization: Yihang Zhao 
Abstract: Multiple oceanic eddies coexist in the North Pacific subtropical front zone (STFZ) in winter, which can be classified into the isolated single eddies (ISO), the combined double isotropic eddies (DBL) and pairs of anisotropic eddies (PAIR). The forcings of these eddies on the mid-latitude atmosphere are investigated using Climate Forecast System Reanalysis (CFSR) data from year 1979 to 2009, which are divided into the remote and local effects in this research. In the stronger STFZ years, there are more ISO and DBL cyclonic eddies to the north but more ISO and DBL anticyclonic eddies to the south of the STFZ, meanwhile more PAIR eddies with cold to the north and warm to the south concentrated around the main axis of the STFZ. These eddy distributions enhance the strength of STFZ, intensify the propagation of upwards baroclinic waves in the lower atmosphere, and finally enhance the zonal wind at upper atmosphere, which is defined as the remote effects of the eddies. However, distinct from this basin-scale remote forcings, three types of oceanic eddies also have different local forcings on the maritime atmospheric boundary layer (MABL) over these eddies. The local effects of the ISO and DBL eddies on MABL entirely depend on the numbers and polarity of the eddy center, while the MABL response to the PAIR eddies appears at the boundary of the two eddies. Furthermore, the local effects of the three types of eddies can be traced to the middle atmosphere accompanied by local precipitation differences. 
Key Words: STFZ; oceanic eddies; remote forcing of eddies; atmospheric baroclinic waves; local forcing of eddies; MABL

\section{Key points:}

1. Multiple oceanic eddies in the North Pacific STFZ exert remote and local forcings on winter mid-latitude atmosphere, which can be classified into the isolated single, the combined double isotropic and pairs of anisotropic eddies;

2. The spatial distribution of these multiple oceanic eddies in STFZ results in the remote forcing on upper troposphere by causing anomalies of basin-scale meridional SST gradient and atmospheric baroclinicity;

3. Three types of multiple oceanic eddies in STFZ have notably different local forcings on the middle and lower atmosphere in winter.

\section{Introduction}

The interaction between the ocean and the atmosphere is the focus of attention in atmospheric dynamics and climate research. It is long been a hot and controversial topic for the air-sea interaction in the mid-latitude, especially for the oceanic forcing on atmosphere (Nakamura et al., 1997; Chelton et al., 2001; Di Lorenzo et al., 2008; Wang et al., 2019; Bai et al., 2019). In the mid-latitude North Pacific, air-sea interaction events can be divided into macroscale climate variability, such as the Pacific Decadal 
Oscillation (PDO) events, and mesoscale, e.g., the impact of oceanic fronts and eddies on the atmosphere above. The PDO is one of the most representative events (Mantua et al., 1997; Mantua \& Hare, 2002) in the mid-latitude Pacific in winter, which performs as a large-scale cool (warm) sea temperature anomaly in the North Pacific associated with the enhancement (decrement) of upper westerly jet stream, during the "warm" ("cool") phase of the PDO. Researches have pointed out that it is more like a forcing from mid-latitude westerly wind to the basin-scale abnormal sea temperature via changing the latent heat of sea surface (Namias, 1969; Palmer, 1985; Deser et al., 1997; Miller \& Schneider, 2000).

Relatively, the forcings of oceanic fronts and eddies to the atmosphere are considered as the representative mesoscale air-sea interactions in the North Pacific (Nakamura et al., 1997; Minobe et al., 2008; Wang et al., 2019; Chen et al., 2019a; Bai et al., 2019, 2020). In the mid-latitude region, the difference between the forcing effects of oceanic fronts and eddies on the atmosphere and the specific physical process remain to be clarified. The most notable mesoscale air-sea interaction characteristic is the positive statistical correlation between SST and near-surface wind speed anomalies (Chelton et al., 2001; Xie, 2004; Small et al. 2005), which was found in global oceanic front regions with large SST gradients and multiple oceanic eddies (the numerous long-lasting coexisted oceanic eddies with various types), including the Kuroshio Extension (KE) (Nonaka and Xie, 2003), 
the Gulf Stream (Minobe et al., 2008; Small et al., 2014), the Antarctic Circumpolar Current (O'Neill et al., 2003) and the Somali Current (Vecchi et al.,2004; Mafimbo et al., 2010).

In the North Pacific, Nakamura et al. $(1997,2004,2010)$ and Wang et al. $(2016,2019)$ stressed the effects of two oceanic fronts on mid-latitude atmosphere, the subtropical front zone (STFZ) and the subarctic front zone (SAFZ). The two oceanic fronts have long been emphasized due to its significant connection with the mid-latitude atmospheric circulation and storm tracks (Nakamura et al., 1997, 2004, 2010). Subsequently, Wang et al. $(2016 ; 2019)$ pointed out that the southern STFZ, which is located between $28^{\circ} \mathrm{N}$ and $32^{\circ} \mathrm{N}$, has the closest relationship with the most significant SST anomaly mode (PDO) in the North Pacific. Their researches revealed that the stronger (weaker) year of the STFZ intensity was accompanied by the PDO warm (cold) phase sea temperature anomaly with the colder (warmer) north and the warmer (colder) south, which increased (weakens) the baroclinity of the lower atmosphere and might affect the upper atmosphere. Furthermore, Chen et al. (2019b) and Chen et al. (2020) pointed out that the STFZ significantly contributes to the variations of atmospheric storm track and westerly jet intensity in midlatitude via changing the vertical propagation of baroclinic Rossby wave and the incidence of barotropic Rossby wave breaking events. This process well reflects the forcing of the interannual variation of the STFZ intensity 
on the middle and upper atmosphere over the entire North Pacific, also known as remote forcing of the STFZ. However, the mechanism of the STFZ interannual variability is still unclear.

The STFZ is believed to be closely related to the North Pacific subtropical countercurrent (STCC), which is an eastward ocean current near the $20^{\circ} \mathrm{N}$ south to the STFZ. Due to the warm water carried by this current from western Pacific to the east, the SST gradient increases from the south to the north (Yoshida et al., 1967; Uda et al., 1969; Roden, 1975). Qiu (1999) suggested that the STCC intensity peaks in late winter and spring, and the intensity change of STCC on the seasonal timescale is mainly due to seasonal surface wind stress forcing. However, it is still unclear whether the variation of STCC could cause the interannual variability of STFZ intensity.

Qiu et al. (2010) suggested that abundant eddy activities with extreme eddy kinetic energy (EKE) distributed along a latitudinal band in the STCC region. Some works also revealed the significant influences of the oceanic eddies on the marine atmospheric boundary layer (MABL) or the lower atmosphere (Kobashi et al., 2008; Minobe et al., 2008; Tokinaga et al., 2009; Small et al., 2008; Ma et al., 2015a; Xu et al., 2016). The MABL is the lower part of the atmosphere, and has large amounts of heat, moisture, and momentum exchanges via turbulent transport, which is directly influenced by the ocean (Fairall et al., 1996). Previous studies (Small et al., 
2008; Ma et al., 2015a; Xu et al., 2016) found that the isolated oceanic eddies in the KE region obviously affect the sea surface wind speed and MABL height locally in winter. Cold (Warm) eddy causes surface winds to decelerate (accelerate) and reduces (increase) latent and sensible heat fluxes, cloud liquid water, water vapor content, and rain rate locally (Ma et al., 2015a). The influences of some steady isolated oceanic eddies are found even propagating to the top troposphere, causing variances of local convection and precipitation (Minobe et al., 2008; Ma et al., 2015a; Zhang et al., 2019; Sun et al., 2020). All these researches emphasize the local effects of an isolated steady eddy (cyclone or anticyclone). However, a large number of oceanic eddies were observed with various forms in the STFZ (Chelton et al., 2007, 2011; Wen et al., 2020). Furthermore, the oceanic eddies are not isolated with each other, which is expressed as more than two oceanic eddies of the same or contrary attributes in a small region (Chelton et al., 2011; Wen et al., 2020). Considering the large number of oceanic eddies in the STFZ region, it is natural to wonder what the relation is between these eddy activities and the STFZ intensity on the interannual time scale. This promising relation may reveal the remote effects of oceanic eddies on mid-latitude upper atmosphere.

Thus, previous studies paid attention to the local forcing of a single oceanic eddy on the lower atmosphere in the STFZ. However, in the STFZ, there are numerous oceanic eddies with complex existing forms (Chelton 
et al., 2011; Wen et al., 2020). Then what are their differences in terms of the local effects on the MABL? Taking the interannual variability of the STFZ intensity as a link, does the spatial distribution of these multiple oceanic eddies have basin-scale remote forcing on the middle and upper atmosphere? To solve above problems, Climate Forecast System Reanalysis (CFSR) dataset was used to analyze the local and remote effects of oceanic eddies in the STFZ on the mid-latitude atmosphere in winter. The rest of the paper is organized as following: $\underline{\text { Section } 2}$ describes data and analysis method. Section 3 reveals the remote forcing of the multiple oceanic eddies in the STFZ on upper atmosphere on the interannual timescale. Section 3.1 shows the observations in the mid-latitude oceanatmosphere system accompany with the STFZ interannual variation; $\underline{\text { Section } 3.2}$ reveals how different types of oceanic eddies in the STFZ result in the remote forcing effect on upper atmosphere in winter. Section 4 compares the differences between the local impacts of isolated and combined oceanic eddies on the middle and lower atmosphere. Section 5 is the discussion and summary.

\section{Data and Analysis Method}

In this study, we used atmosphere and ocean reanalysis outputs of Climate Forecast System Reanalysis (CFSR) data in winter (DJF, i.e. Dec., 
Jan. and Feb.) from 1979 to 2009. This global, coupled and high-resolution product provided by the National Centers for Environmental Prediction (NCEP) has long been credited for its accurate estimation of the atmosphere and the ocean (Xue et al.,2011; Carvalho et al., 2012; Ma et al, 2015a). The CFSR Selected Hourly Time-Series Products (ds093.0) last 32 years from 1979 to 2010 with the 6-hourly time resolution and the $0.5^{\circ} \times 0.5^{\circ}$ spatial horizontal resolution. The CFSR oceanic outputs have 40 levels from 5-meter to 4478-meter, in which top 20 levels are used in this study covered from ocean surface (5-meter) to 205-meter. The CFSR atmospheric outputs have multiple vertical coordinates. Surface parameters such as 2-meter temperature, 10-meter winds, sensible heat flux (SHF), latent heat flux (LHF), MABL height, frictional velocity and precipitation are used in our study. Several specific vertical layers of wind and geopotential height data are selected to investigate higher atmosphere. CFSR 6-hourly earth-system reanalysis outputs with the $0.5^{\circ} \times 0.5^{\circ}$ spatial resolution should be enough to detect eddies since the large eddies in this region have a typical mean eddy diameter of $200 \mathrm{~km}$ (see Fig. 3c in Chelton et al., 2007). Furthermore, to catch more details of approximate eddy center and moving locus, the spatial horizontal resolution is bilinearly interpolated to $0.25^{\circ} \times 0.25^{\circ}$ in this study. All the correlation analysis and eddy composited analysis use daily mean of the 6-hourly outputs.

To quantitatively identify the boundary and stronger or weaker years 
of the STFZ, we calculated the STFZ intensity index (ITS) for each winter, which is defined in Wang et al. (2019). According to the climatological wintertime meridional SST gradient distribution (Fig. 1), a prominent large value and a relatively strong zone of zonal mean gradient locate at $28^{\circ} \mathrm{N}$ and $41^{\circ} \mathrm{N}$ respectively. The STFZ is defined as the region in the subtropics where the average temperature gradient is above $0.6{ }^{\circ} \mathrm{C} /$ degree. And then the magnitude of the SST gradient in this box of $24^{\circ} \mathrm{N}-32^{\circ} \mathrm{N}, 140^{\circ} \mathrm{E}-$ $140^{\circ} \mathrm{W}$ is defined as the intensity of the STFZ. The ITS of the STFZ are basically calculated by spatially averaging meridional SST gradient of the STFZ region, and the formula (Wang et al., 2019) goes that

$$
\text { ITS }=\frac{\sum \mathrm{G}_{\mathrm{i}}}{\mathrm{N}}
$$

where $G_{i}$ is the value of zonally-averaged SST meridional gradient at the $\mathrm{i}$-th latitudinal grid point within the zone, and $\mathrm{N}$ is the number of total grid points within the latitude/longitude box above. The oceanic current EKE is calculated by

$$
\mathrm{EKE}=0.5 \times\left(\mathrm{u}^{\prime 2}+\mathrm{v}^{\prime 2}\right)
$$

where $u$ and $v$ represent the zonal and meridional current speed respectively, $u^{\prime}$ represents the perturbation term, $u^{\prime}=u-\bar{u}$, $\bar{u}$ represents time-average of zonal current velocity in winter, $\bar{u}=$ $\frac{1}{N_{\text {days }}} \sum u$, and superscript of the $v$ is similar to the $u$. Furthermore, we defined the EKE index by spatial average of 3-7 days bandpass filtered sea surface EKE in the eddy locations, which is defined by masking out those 
sea areas with no eddy formation of the STFZ region $\left(24^{\circ} \mathrm{N}-32^{\circ} \mathrm{N}, 140^{\circ}\right.$ E-140 ${ }^{\circ} \mathrm{W}$ ) each winter. Thus, the formula of EKE index goes that

$$
\mathrm{EKE} \text { index }=\frac{\sum \mathrm{EKE}_{\mathrm{i}}}{\mathrm{N}}
$$

where $\mathrm{EKE}_{\mathrm{i}}$ is the value of 3-7 days bandpass filtered sea surface EKE at the $\mathrm{i}$-th latitudinal grid point within the zone, and $\mathrm{N}$ is the number of total grid points within the latitude/longitude box above. Similarly, the STCC index is defined by the zonal mean u-component of current at sea surface in $18^{\circ} \mathrm{N}-24^{\circ} \mathrm{N}, 140^{\circ} \mathrm{E}-157^{\circ} \mathrm{W}$. To clarify the features of wind speed distribution, we analyzed the scalar wind representing the variance of wind speed including the wind EKE (Bai et al., 2019), which is defined as

$$
V_{\text {scalar }}=\frac{1}{N_{t s}} \sum_{i=1}^{N_{t s}} \sqrt{\left(\bar{u}+u_{i}^{\prime}+u_{\varepsilon i}\right)^{2}+\left(\bar{v}+v_{i}^{\prime}+v_{\varepsilon i}\right)^{2}}
$$

where $u$ and $v$ represent the zonal and meridional wind speed respectively, the subscript $i$ represents the output data on each moment, $\bar{u}$ represents time-average of zonal wind velocity within eddy duration, $u_{i}^{\prime}$ represents the perturbation term, $u_{i}{ }^{\prime}=u_{i}-\bar{u}, u_{\epsilon i}$ represents the remainder term, and $N_{t s}$ is total number of time steps. Besides, the data interval in daily, so the $u_{\epsilon i}$ represents the disturbance within 24 hours and other remainder components (Bai et al., 2019). The subscript and superscript of the $v$ are similar to the $u$. Moreover, to verify the vertical mixing and dynamic instability, we calculated the gradient Richardson number (Chan, 2008) in this study, which is defined as 


$$
R_{i}=\frac{\frac{g \partial \theta_{v}}{T_{v} \partial z}}{\left(\frac{\partial U}{\partial z}\right)^{2}+\left(\frac{\partial V}{\partial z}\right)^{2}}
$$

where $\theta_{v}$ is virtual potential temperature, $T_{v}$ is virtual absolute temperature, $\mathrm{z}$ is height, $\mathrm{g}$ is gravitational acceleration, and $(\mathrm{U}, \mathrm{V})$ are the wind components toward the east and north. The critical Richardson number, Ric, is about 0.25 (although reported values have ranged from roughly 0.2 to 1.0 ), and flow is dynamically unstable and turbulent when $\mathrm{Ri}<$ Ric. Such turbulence happens either when the wind shear is great enough to overpower any stabilizing buoyant forces (numerator is positive), or when there is static instability (numerator is negative).

To detect eddies in CFSR outputs, we used the geometry-based detection algorithm of velocity vector filed (Nencioli et al., 2010). The minimum velocity is found at approximate center of the eddy and tangential velocity increases linearly away from it till coming to a peak then decreasing, and the distance of increment is considered as eddy radius. Besides, the directions of current should rotate in a consistent orientation or tendency. This can be quantitatively implemented by separate analyzing $\mathrm{u} \& \mathrm{v}$ component of current (the zonal and meridional current speed respectively) and constraining adjoining velocity vectors into same or adjacent quadrants. Locations of eddy centers and each estimated spatial extent can be identified through the six constraints referred to Wen et al. (2020). The grids satisfying the six conditions are automatically determined as the eddy center and the corresponding radius will be given 
in grid numbers. Considering only one component of $\mathrm{u} / \mathrm{v}$ in four directions (north, south, west, and east) would make the determined radius smaller than the actual radius, we used the current velocity to determine radii in four directions.

CFSR has been proved as an ideal product for this method with its high spatial and temporal continuity (Wen et al., 2020). Furthermore, Wen et al. (2020) compared the interpolated $0.25^{\circ} \times 0.25^{\circ} \mathrm{CFSR}$ and the finer $1 / 6^{\circ} \times 1 / 6^{\circ}$ HYCOM global assimilation data (Global HYbrid Coordinate Ocean Model and the Navy Coupled Ocean Reanalysis DataGLBv0.08/expt_53.X). The interpolated CFSR data has comparable results with the HYCOM when dealt with the same eddy detection method. Since the results are presented day by day when using daily average data, we selected those located in the STFZ and lasted for 3 days within a $2^{\circ} \times 2^{\circ}$ box, then we filtered top $50 \%$ as valid eddies by their strengths. In addition, we defined the absolute value of spatially averaged SST anomaly as the strength of eddy. The valid eddies are incorporated into our eddy dataset to present composite effects of oceanic eddies more clearly, the results from all eddies are similar. 


\section{Remote Forcing of multiple oceanic eddies on Wintertime Mid- latitude Atmosphere in the North Pacific on the interannual timescale}

3.1 Observations of mid-latitude ocean and atmosphere associated with STFZ interannual variation

The impacts of the artificially separated mesoscale SST anomalies using low-pass filter were often regarded as the forcing effects of multiple oceanic eddies in the numerical experiments (Ma et al., 2015b, 2017; Sun et al., 2018; Foussard et al., 2019). Is there an approach to capture them in the observations? The observed oceanic eddies distributed confusedly in the North Pacific, which is manifested as the synchronous coexistence of multiple oceanic eddies (Chelton et al., 2007, 2011; Wen et al., 2020). Especially in the STFZ region, previous works discussed the forcing effects of STFZ intensity variations on above mid-latitude atmosphere (Wang et al., 2016, 2019; Chen et al., 2019b; Chen et al., 2020). However, the causes of interannual variation of STFZ intensity are not clear. As mentioned in the introduction, the STCC south to the area, which carries the warm water to the central and eastern Pacific, has close relations to the maintenance of the STFZ. Meanwhile, the abundant presence of oceanic eddies appears in the sea surface of the STFZ and the region farther north (Fig. 1a). Distinct to sea surface, the STFZ intensity has comparable strength to the norther 
SAFZ in the subsurface layer, and its position moves southerly (ig. 1b). Considering the 3-7 day bandpass-filtered (Duchon,1979; Russell, 2006) EKE in Fig. 1b, representing the synoptic-scale oceanic eddy activities, mainly exists near $25^{\circ} \mathrm{N}$, which coincides the latitude of the STFZ in the subsurface layer. The above results indicate that the variation of the STFZ may be affected by multiple synoptic-scale oceanic eddies, besides the influence of the STCC (detailed mechanism in Section 3.2).

(a) Surface temp.grad. \& current

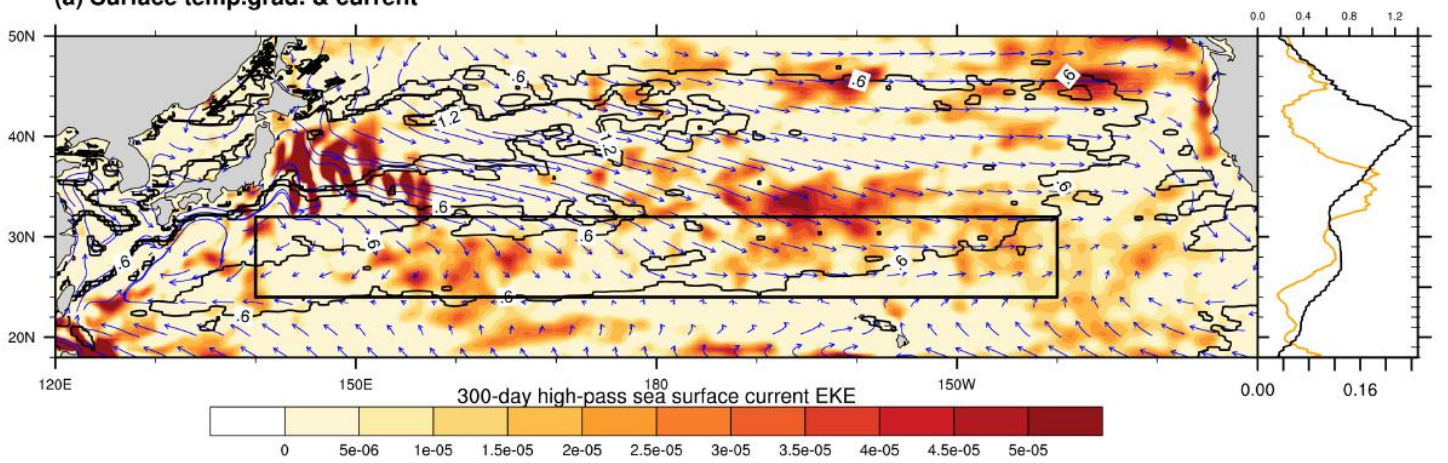

(b) Subsurface temp.grad. \& current

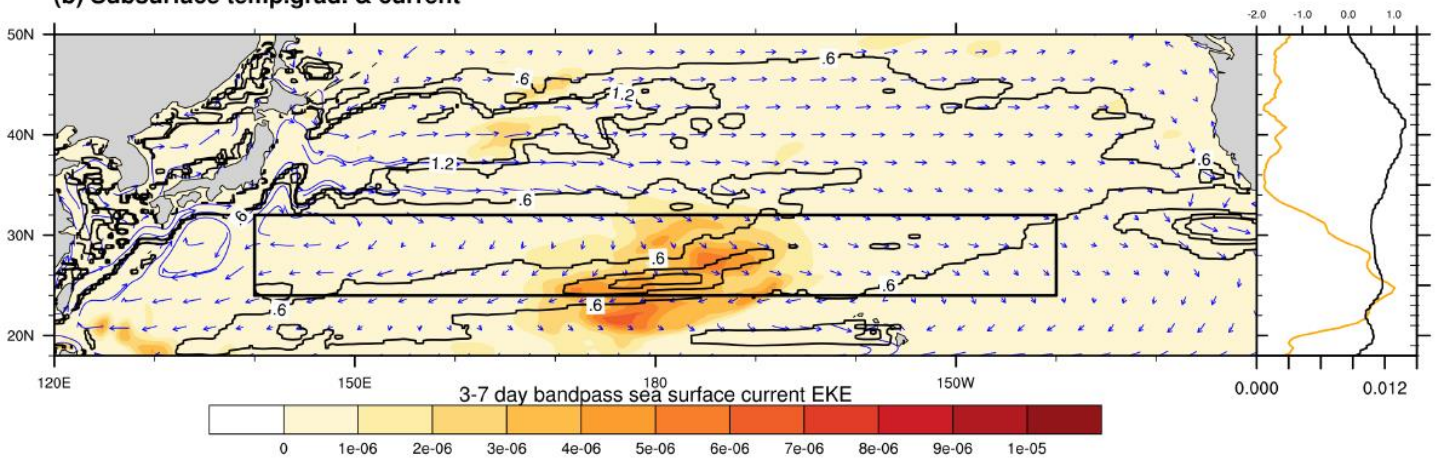

Fig 1. Filtered sea surface EKE (shadings, units: $\mathrm{m}^{2} \mathrm{~s}^{-2}$, a: 300-day high-pass; b: 3-7 day bandpass) with averaged meridional sea temperature gradient (contours, $-\partial \mathrm{T} / \partial \mathrm{y}$, units: ${ }^{\circ} \mathrm{C} /{ }^{\circ}$, a: surface; b: $105 \mathrm{~m}$ depth) and current velocity (vectors, a: surface; b: 105m depth) in DJF from 1979 to 2009. The STFZ region is outlined by the black box. Attached solid lines are zonal mean of corresponding filtered EKE (X bottom axis, units: $10^{-4} \cdot \mathrm{m}^{2} \mathrm{~s}^{-2}$, color: orange) and zonal mean of corresponding meridional temperature gradient from $140^{\circ} \mathrm{E}$ to $140^{\circ} \mathrm{W}$ (X top axis, units: ${ }^{\circ} \mathrm{C} /{ }^{\circ}$; color: black).

The characterization index of oceanic eddies is introduced in Formula 
(2) to present the interannual variability of the ocean current EKE. And to quantify the correlations, Fig. 2 shows the standardized time series of the ITS, STCC and EKE indexes. The EKE index and STCC index represent the activities of oceanic eddies in STFZ region and the STCC latitudinal current strength, respectively. The correlation coefficient between EKE index and ITS reaches to 0.41 , which passed $95 \%$ t-test significant level. However, the correlation coefficient between STCC index and ITS is only 0.12 . These results show that the interannual variability of STFZ intensity has a close linkage to the oceanic eddies, while the STCC has little effect on it. The STFZ intensity shows an obvious interannual variability, then what happens in response to its enhancement? Then we composited the differences of several atmospheric fields between the stronger (1980, 1985, 1986, 1995, 2002, 2005, 2009) and weaker years $(1990,1992,1994,1998$, 1999, 2008) of the STFZ intensity, using the 1.0 standard deviation of ITS. 


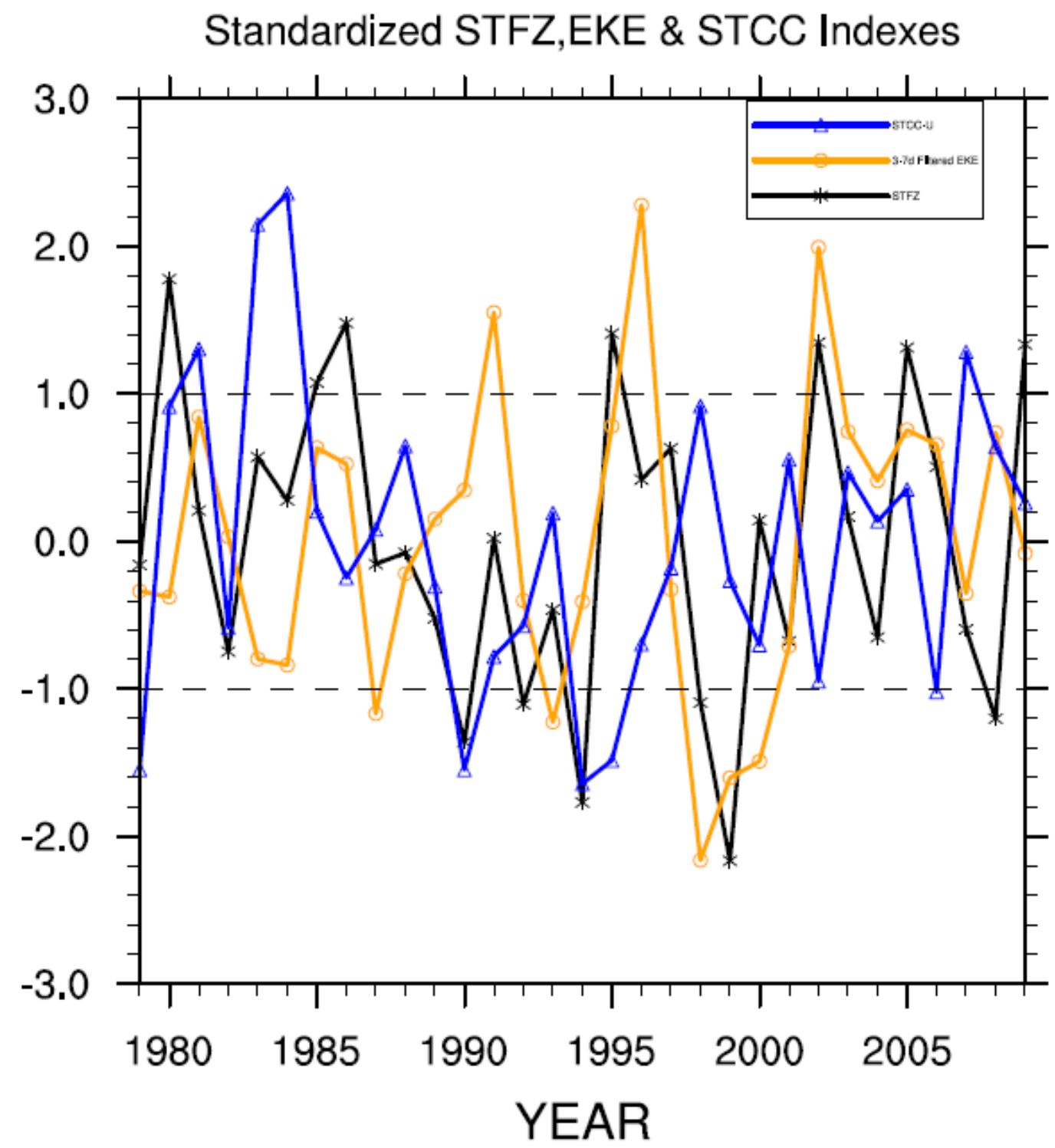

Fig 2. Standardized time series of the ITS (black), EKE (orange) index and U-component of STCC index (blue). The ITS, EKE index, and U-component of STCC index are the spatial average of the SST gradient in $24^{\circ} \mathrm{N}-32^{\circ} \mathrm{N} \& 140^{\circ} \mathrm{E}-140^{\circ} \mathrm{W}, 3-7$ days bandpass filtered sea surface EKE in the eddy locations within STFZ, and u-component of current at sea surface in $18^{\circ} \mathrm{N}-24^{\circ} \mathrm{N} \& 140^{\circ} \mathrm{E}-$ $157^{\circ} \mathrm{W}$, respectively. The reference lines are $\pm \sigma$. X-axis presents the years; Y-axis presents the standardized indexes.

The oceanic fronts (STFZ and SAFZ) with larger SST gradients are the most significant areas among mid-latitude air-sea interactions (Nakamura et al., 1997; Minobe et al., 2008). The differences of the SHF, LHF, Eady growth rate at $850 \mathrm{hPa}$, averaged storm tracks $\overline{\left(\mathrm{v}^{\prime 2}\right.}$, synoptic- 
scale transient eddy) and u-component of wind at $300 \mathrm{hPa}$ between stronger and weaker years of the STFZ are shown in the Fig. 3 . The SHF and LHF have positive anomalous responses, which are caused by the larger SST gradient that even bring intense heat exchange and air-sea humidity differences (Fig. 3a, 3b). Corresponding air temperature change occurs in the lower atmosphere and brings the positive baroclinity (Eady growth rate) response mainly takes place in the region between the STFZ and SAFZ, while the negative value exists north to the SAFZ (Fig. 3c). Chen et al. (2019b) pointed out that the temperature gradient anomaly in the lower atmosphere could generate upward baroclinic waves and energy transport. As results of this process, the u-component of wind was notably increased at $300 \mathrm{hPa}(\underline{\text { Fig. } 3 \mathrm{e}})$ and the storm track had significant positive anomaly at the exit of the westerly jet (Fig. 3d). Therefore, the STFZ intensity anomaly changes the turbulent heat flux (SHF, LHF) in the air-sea interface, causes the temperature gradients and baroclinity anomalies in the lower atmosphere, leads to the abnormal fluctuations of the upward baroclinic Rossby wave and baroclinic energy transport, finally affects the upper storm track and jet stream. Chen et al. (2020) revealed the similar process using the numerical experiments. As seen from Fig. 2, the responses in upper troposphere closely related to the oceanic EKE variation, which are defined as the remote effects of the oceanic eddies in this work. Since the large value of oceanic EKE usually accompanies with complicated 
distributions of oceanic eddies, how do the complicated eddies cause the regularly enhancing or decreasing of the STFZ intensity?

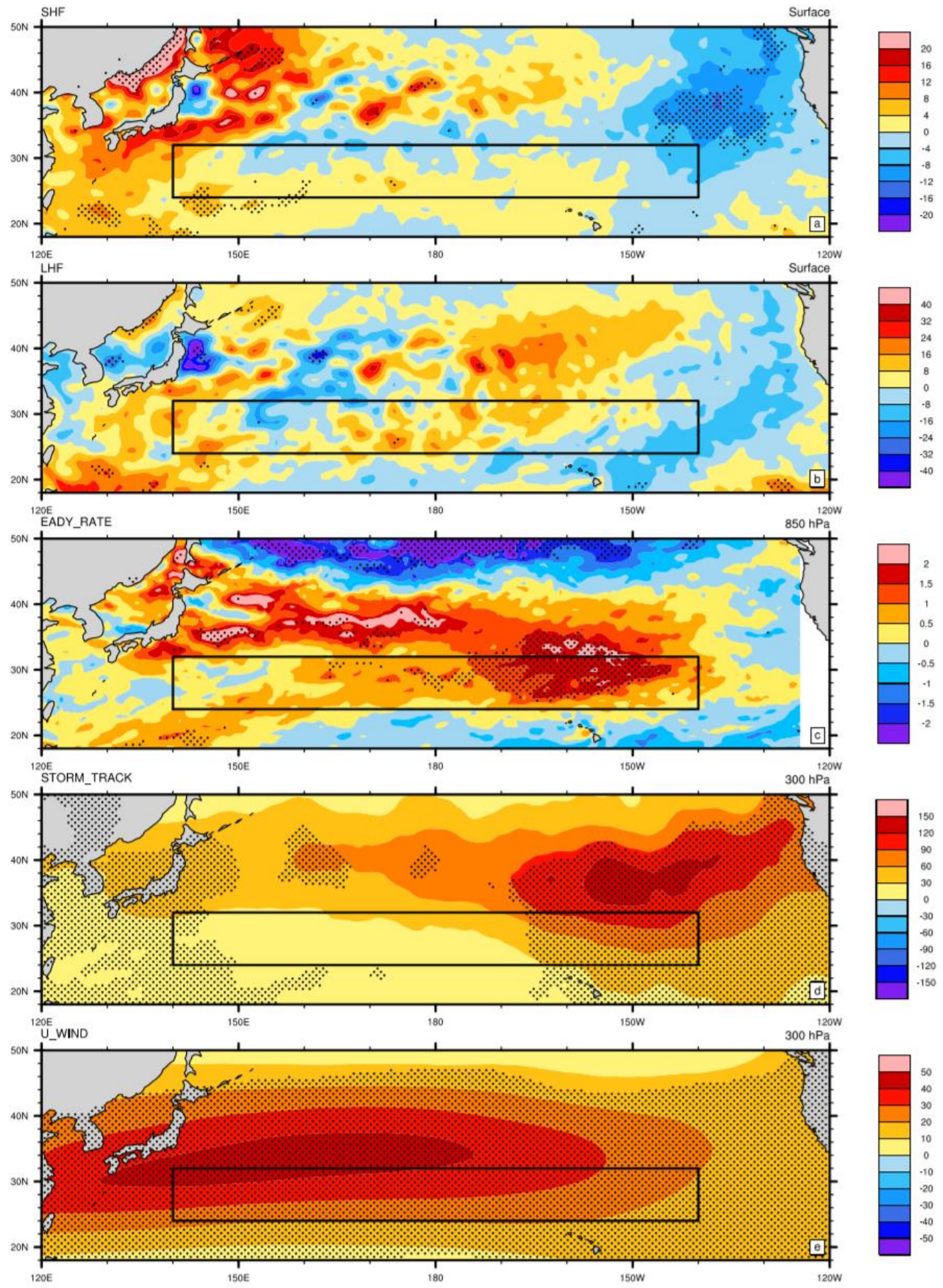

Fig 3. Difference of averaged (a) SHF (units: $\mathrm{W} \cdot \mathrm{m}^{-2}$ ), (b) LHF (units: $\mathrm{W} \cdot \mathrm{m}^{-2}$ ), (c) Eady growth rate (units: $10^{-5} \mathrm{~m} \cdot \mathrm{s}^{-2}$ ), (d) storm track at $300 \mathrm{hPa}$ (units: $\mathrm{m}^{2} \mathrm{~s}^{-2}$ ), (e) u-component of wind at $300 \mathrm{hPa}$ (units: $\mathrm{m} \cdot \mathrm{s}^{-1}$ ) between stronger and weaker years of the STFZ. The STFZ region is outlined by the black 
box. Dotted areas have passed 95\% t-test significant level.

3.2 How multiple eddies caused the Remote Forcing Effects by changing the STFZ strength

In the previous section, we found that the collaborated anomalous SST gradients induced by the multiple oceanic eddies have good correlation with the STFZ intensity, and exert remote forcing on upper atmosphere by the baroclinic adjustment process in the mid-latitude atmosphere. However, previous studies (Qiu 1999; Qiu et al., 2010, 2014) also emphasized the relationship between STFZ and STCC on the seasonal timescale. Fig. 4 displays SST gradient anomaly, oceanic eddies and mean oceanic current (STCC) in winter of each stronger ( $\underline{\mathrm{a}-\mathrm{e}})$ and weaker $(\underline{\mathrm{f}-\mathrm{j}})$ years of the STFZ intensity. The results show that the numbers and strengths of oceanic eddies are irregular. The zonal mean current velocity of u-component between $140^{\circ} \mathrm{E}$ and $157^{\circ} \mathrm{W}$ (solid green lines) shows an interannual variability, but it does not coincide with the STFZ intensity variance (red or blue lines). For instance, the STCC anomalies do not match the variation of STFZ intensity during the stronger $(1999,2008$; Fig. 4-i2, 4-j2) or weaker (1986, 1995; Fig. 4-a2, 4-b2) years. In other words, the stronger (weaker) STFZ does not correspond to the specific stronger (weaker) STCC on the interannual time scale. On the other hand, although there is a high correlation between the STFZ intensity and EKE values of oceanic eddies, 
the attributes of oceanic eddies perform stochastic, no matter considering the strength or vorticity of eddies. So how do the oceanic eddies specifically cause the changing of STFZ? Is it a causal connection?

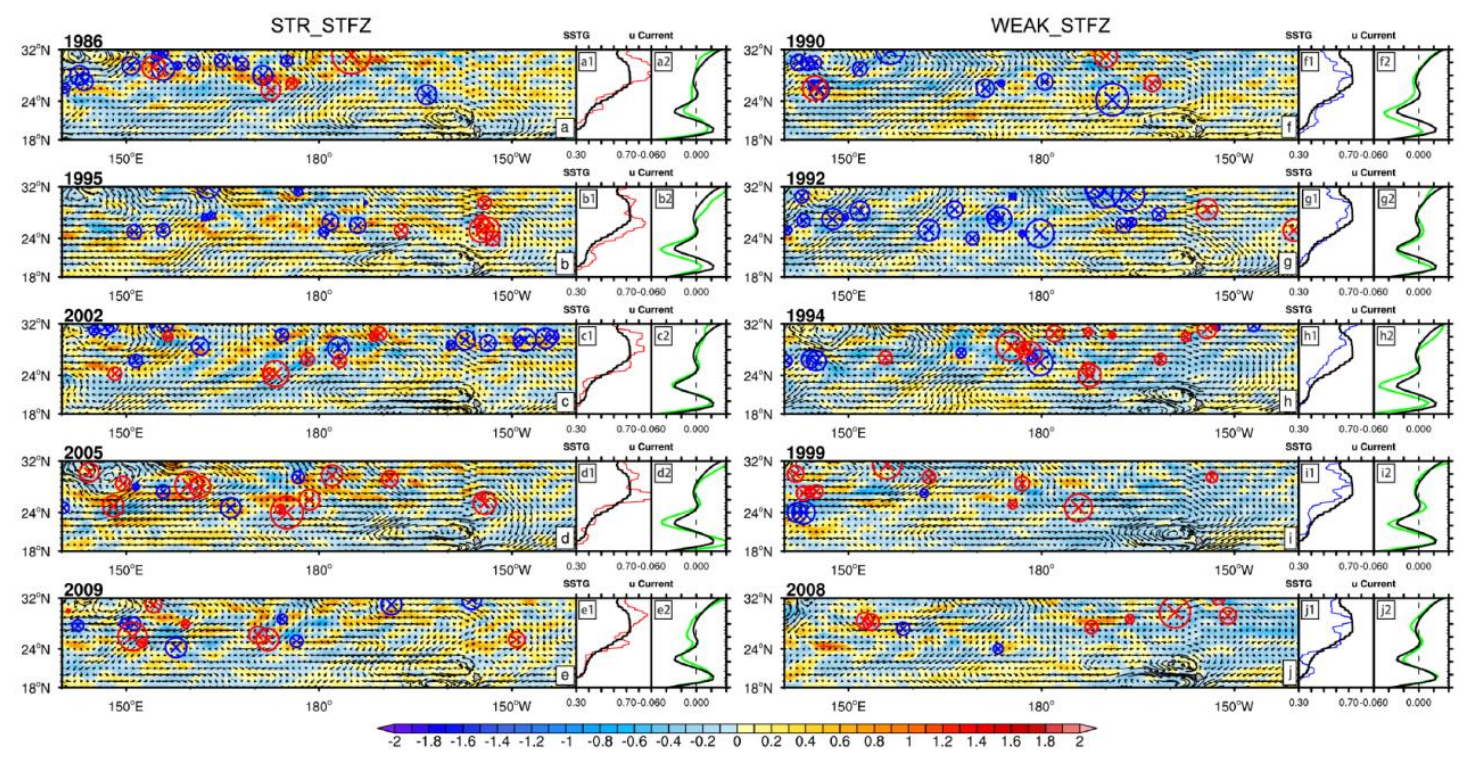

Fig 4. Comparison of eddy occurrences in stronger (a-e) and weaker (f-j) of STFZ intensity years. Blue (Red) marker represents cyclone (anticyclone) eddies. Meridional SST gradient anomaly (shadings, units: ${ }^{\circ} \mathrm{C} /{ }^{\circ}$ ) and averaged current velocity (vectors, units: $\mathrm{m} \cdot \mathrm{s}^{-1}$ ) from surface to $205 \mathrm{~m}$ of the year are also given in pictures. (a1-j1) present zonal means of meridional SST gradient, black solid line is average from all 31 years, red or blue line is average of the stronger or weaker STFZ year; (a2-j2) present zonal means of current u-component from $140^{\circ} \mathrm{E}$ to $157^{\circ} \mathrm{W}$, black solid line is the average value of all 31 years, green line is the value of the respective year.

The existing forms of eddies in real ocean are complicated, including an isolated cyclonic or anticyclonic eddy and different kinds of combinededdies. The combined-eddies are defined as two oceanic eddies existing longitudinally within a $5^{\circ} \times 5^{\circ}$ box, which include the combined doublecyclones, the combined double-anticyclones, and the combined cycloneanticyclone pairs. Here we list three major groups in Table 1.

Table 1. Eddy Groups 


\begin{tabular}{lccc}
\hline Groups & Cases & Percentage & abbreviation \\
\hline $\begin{array}{l}\text { The isolated single eddy (cyclone or } \\
\text { anticyclone) }\end{array}$ & 758 & $74.0 \%$ & ISO \\
$\begin{array}{l}\text { Double isotropic eddies (cyclones or } \\
\text { anticyclones) }\end{array}$ & 180 & $17.6 \%$ & DBL \\
$\begin{array}{l}\text { A pair of anisotropic eddies (with } \\
\text { contrary SST anomalies) }\end{array}$ & 86 & $8.4 \%$ & PAIR \\
\hline
\end{tabular}

Since the abnormal STFZ intensity is defined by the change of SST gradients, we need to display the more detailed local meridional SST gradient caused by each group of oceanic eddies. After masking those regions without steady oceanic eddies in winter, Fig. 5 shows the positions of the ISO, DBL and PAIR eddies (normal, green and purple) and the zonal mean of SST gradient anomalies caused by them. Overall, there are three groups of oceanic eddies in each year, although the number of DBL and PAIR eddies is smaller. Specially in the year 2002, the DBL and PAIR eddies, significantly exist near $30^{\circ} \mathrm{N}$ (Fig. 5c2). In total, the zonal mean of the meridional SST gradient anomalies over the eddy locations matches better with STFZ intensity anomalies than the areas without any eddies. As a comparison, the zonal mean SST gradient anomalies in those regions without eddies is nearly zero (see Supplementary Materials Figure S1). It indicated that the multiple oceanic eddies may lead to the interannual variation of STFZ intensity by changing the SST gradient anomalies significantly in the eddy locations with certain spatial distributions. As for the stronger and weaker years of the STFZ intensity, Fig. 5 also shows that DBL and PAIR eddies have greater positive anomalous SST gradient than 
ISO in stronger years of the STFZ intensity, and they have nearly equivalent negative anomalous SST gradient during the weaker years. The ISO, DBL and PAIR eddies all contribute to the abnormal STFZ intensity in these years. Although the combined eddies (including DBL and PAIR) make up less than $30 \%$, their impact is significant. The anomalous STFZ intensity with DBL has greater variations than the original STFZ, whereas the variation of anomalous STFZ intensity in the other region is significantly reduced. Such as in the stronger year 2002 of the STFZ intensity, it is precisely because of the existence of the DBL and PAIR that the intensity of STFZ increases significantly. If the DBL (PAIR) is removed, the anomalous intensity of STFZ will decrease $35.4 \%$ (30.7\%) in this year. (see Supplementary Materials Figure S2-4). Therefore, the oceanic eddies (with complex existing forms) and the interannual variability of STFZ intensity are closely related.

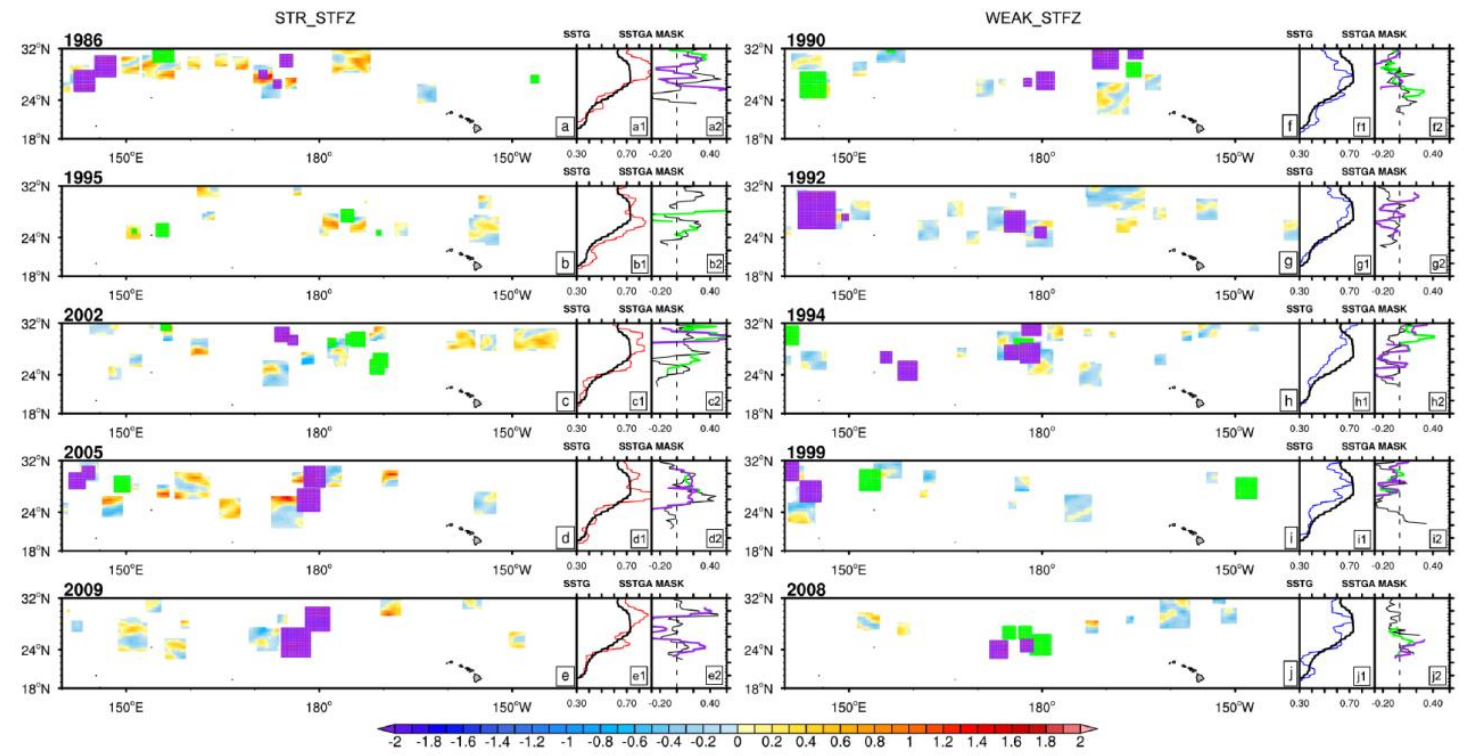

Fig 5. Comparison of eddy occurrence in stronger (a-e) and weaker (f-j) years. Meridional SST 
gradient anomaly (shadings, units: ${ }^{\circ} \mathrm{C} /{ }^{\circ}$ ) are masked out in eddy positions. (a1-j1) present zonal means of meridional SST gradient from $140^{\circ} \mathrm{E}$ to $140^{\circ} \mathrm{W}$, black solid line is average from all 31 years, red and blue lines are average of the stronger or weaker STFZ year. (a2-j2) present zonal means of meridional SST gradient anomaly caused by the ISO eddies (black), the DBL (green) and the PAIR (purple) eddies. The cell-shading ones are the positions of DBL (green) and PAIR (purple) eddies. The ones with normal shadings are ISO eddies.

Thus, what kind of eddy distributions led to this result? To answer the question, the distributional characteristics of the cyclonic and anticyclonic eddies are presented in Fig. 6 in the stronger, normal and weaker years of the STFZ intensity. Defining $28^{\circ} \mathrm{N}$ as the central axis of STFZ, in the stronger years of STFZ, more cyclone (anticyclone) eddies locate north (south) of $28^{\circ} \mathrm{N}$ (Fig. 6a), cooling (warming) the sea area north (south) of $28^{\circ} \mathrm{N}$, intensifying the overall SST gradient. In the weaker years of STFZ intensity, more cyclone (anticyclone) eddies occur south (north) of $28^{\circ} \mathrm{N}$ (Fig. 6c), reducing the overall SST gradient. While in the STFZ intensity normal years, the distributions of cyclone and anticyclone eddies are totally stochastic (Fig. 6b), which barely change the SST gradient.
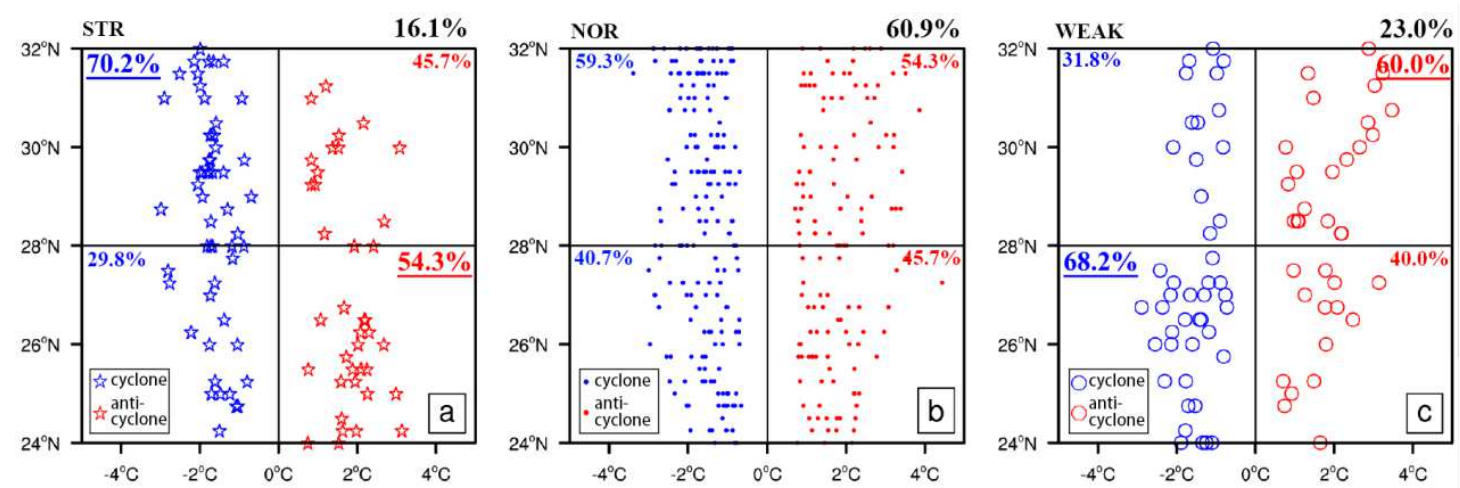

Fig 6. Spatial distribution and ratio of eddies in (a) stronger, (b) normal, and (c) weaker years of the STFZ. For all eddies in 31 years, $16.1 \%$ eddies occur in stronger STFZ years; $60.9 \%$ and $23.0 \%$ for normal and weaker years, respectively. Obviously, most cyclone eddies occur north (south) to $28^{\circ}$ $\mathrm{N}$ with $70.2 \%(68.2 \%)$ of total cyclones in the stronger (weaker) STFZ intensity years, while 
anticyclone eddies occur north (south) to $28^{\circ} \mathrm{N}$ with $60.0 \%(54.3 \%)$ in the weaker (stronger) years.

Fig. 7 further shows the spatial distribution and ratio of each group of eddies (ISO, DBL, PAIR) in stronger, normal, and weaker years of the STFZ intensity. Also defining $28^{\circ} \mathrm{N}$ as the central axis of STFZ, in the stronger years of STFZ, more cyclone (anticyclone) ISOs locate north (south) of $28^{\circ} \mathrm{N}$ (Fig. 7a), cool (warm) the sea area north (south) of $28^{\circ} \mathrm{N}$, intensifying the overall SST gradient. In the weaker years of STFZ intensity, more cyclone (anticyclone) ISOs occur south (north) of $28^{\circ} \mathrm{N}$ (Fig. 7c), reducing the overall SST gradient. The situation is the same for DBLs (Fig. 7d-f), although there are fewer eddy cases. However, it is obvious that the difference in the north-south percentage of cyclones and anticyclones caused by DBL is more significant than that of ISO. For the longitudinally combined cyclone-anticyclone pairs (cold to the north and warm to the south, orange markers in Fig. $7 \mathrm{~g}-\mathrm{i}$ ) and the reversed anticyclone-cyclone ones (green), they can induce the increasing and decreasing of local temperature gradient, respectively. In the stronger years, the PAIR located closer to the central axis of STFZ (Fig. 7g), benefiting the stronger STFZ intensity. However, in the weaker years, the PAIR dispersed away from the central axis (Fig. 7i), offering insufficient temperature gradient. The above results can explain that the multiple eddies with divergent patterns can lead to the variability of the STFZ intensity. 

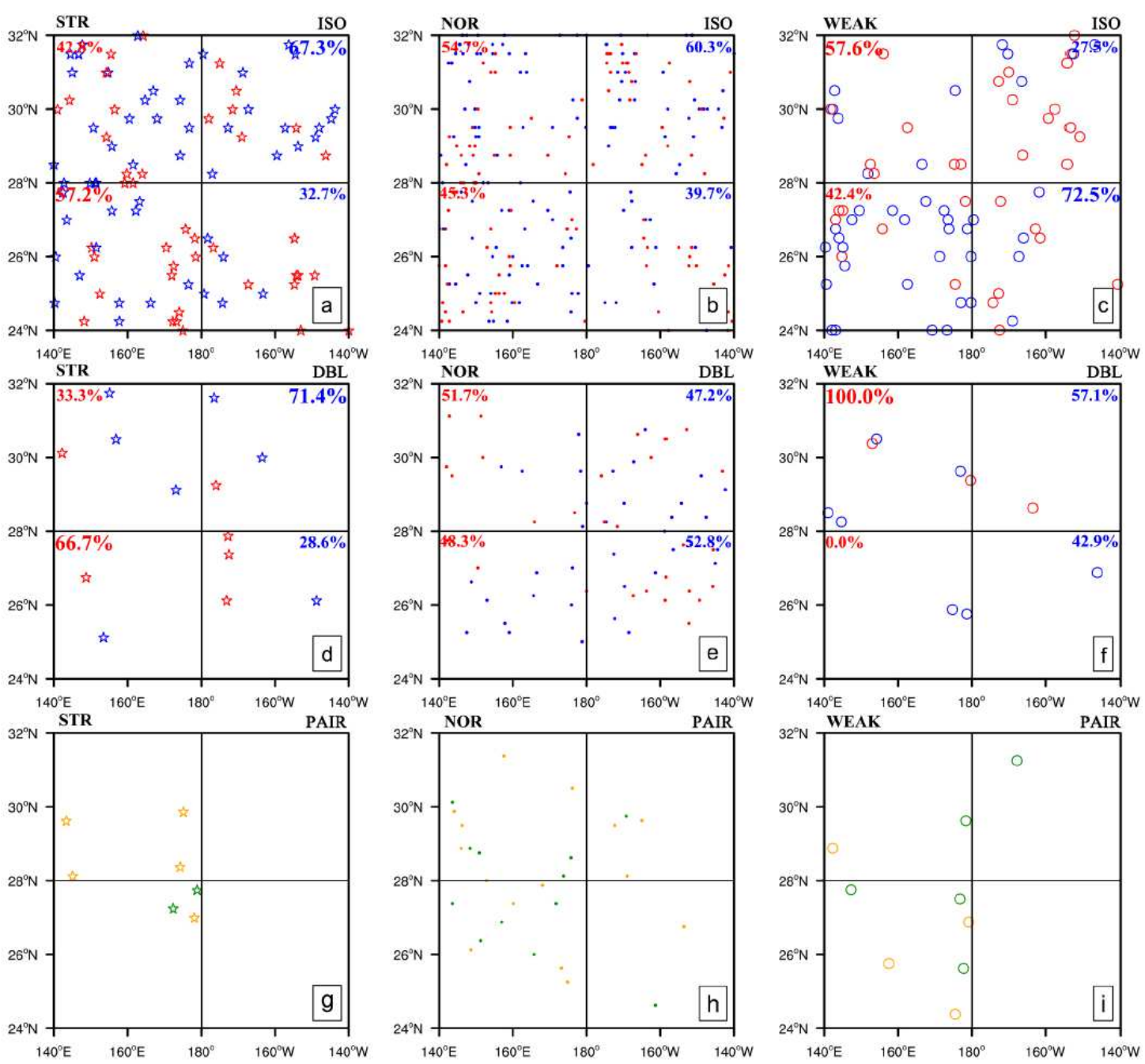

Fig 7. Spatial distribution and ratio of eddies in (a, d, g) stronger, (b, e, h) normal, and (c, f, i) weaker years of the STFZ. (a-c) for ISO, (d-f) for DBL and (g-i) for PAIR eddies. ISO eddies perform almost the same as that in Fig. 6, and more significant percentage characteristics appear for DBL eddies. For the PAIR eddies, longitudinal cyclone-anticyclone pairs (cold to the north and warm to the south) are presented with orange markers of (g-i) and longitudinal anticyclone-cyclone pairs (warm to the north and cold to the south) are presented with green markers of (g-i).

In summary, we found a significant connection between the STFZ intensity and EKE values of oceanic eddies over North Pacific in winter. Furthermore, considering the upper atmospheric subsequent responses to STFZ intensity change, the STFZ intensity can be considered as a link between the multiple oceanic eddies and the remote effect on the upper 
atmosphere in the mid-latitude. The abnormal SST gradient induced by the spatial distributions of three types of eddies provide a firm evidence to the interannual variability of the STFZ intensity. Therefore, the multiple oceanic eddies in the STFZ will exert remote forcings on upper atmosphere by causing anomalies of the basin-scale SST gradient, the atmospheric baroclinicity and the upward baroclinic waves, which are not happened overnight. The local forcings of the three types of eddies on the MABL and lower atmosphere should be considered as the fundamentals.

\section{Local Forcings of the Complex Eddy Combinations to the Middle and Lower Atmosphere}

In $\underline{\text { Section } 3}$, we have discussed the different distribution types of oceanic eddies in the STFZ region. By changing the meridional temperature gradient over the eddy locations, these eddies lead to the remote effect on the upper atmosphere in the mid-latitudes, which should base on the direct local forcing on the MABL firstly. Considering the three main types of the multiple oceanic eddies, the forcings of them on MABL are still unclear. Previous researches have emphasized that a single strong eddy exerts local forcing on the atmospheric boundary layer (Small et al., 2008; Ma et al., 2015a; Xu et al., 2016). As mentioned above, the existing forms of eddies in STFZ are complicated, including the ISO, DBL and 
PAIR eddies. The details of numbers and percentages of these eddy events are listed as Table 2. The impacts of these complex eddy combinations on MABL are distinct obviously. The isolated single cyclone eddies (39.9\%), isolated single anticyclone eddies (34.1\%) and the total combined eddies including both DBL and PAIR (26\%) are of the same magnitude. Since the isolated eddy cases and combined-eddies have been distinguished, we made investigation via composite analysis, considering the diversity and heterogeneity of eddies in the five situations.

Table 2. The Numbers of Different Eddy Events

\begin{tabular}{llccc}
\hline Groups & Eddy scenarios & Cases & Percentage & abbreviation \\
\hline ISO & Isolated single cyclone eddy & 409 & $39.9 \%$ & ISO_CYC \\
& Isolated single anticyclone eddy & 349 & $34.1 \%$ & ISO_ANT \\
\hline \multirow{2}{*}{ DBL } & Combined double-cyclone eddies & 100 & $9.8 \%$ & DBL_CYC \\
& Combined double-anticyclone eddies & 80 & $7.8 \%$ & DBL_ANT \\
\hline \multirow{2}{*}{ PAIR } & Cold (cyclone) eddy to the north and & 48 & $4.7 \%$ & PAIR_NC_SW \\
& warm (anticyclone) eddy to the south & & & \\
& Warm (anticyclone) eddy to the north & 38 & $3.7 \%$ & PAIR_NW_SC \\
& and cold (cyclone) eddy to the south & & & \\
\hline
\end{tabular}

For isolated single cyclone eddies (ISO_CYC), the negative anomalies of 2-meter air temperature and 10-meter wind speed appear near SST negative anomaly center (Fig. 8a, 8e), revealing that cold oceanic eddies would lead to surface air cooling and wind deceleration. Furthermore, the negative anomaly centers of both SHF and LHF as well 
as MABL height are in-phase with SST anomaly (Fig. 8b-8d). Besides, the surface frictional velocity (Fig. 8f) shows an in-phase negative anomalous center with SST. The above results are consistent with previous studies (Ma et al., 2015a; Sun et al., 2020), indicating that the recognition and effects of oceanic eddies under the CFSR reanalysis outputs are in good agreement with the previous data results. Moreover, we made further investigation on the 10-meter scalar wind (Fig. 8h), and the anomalies are greater than average wind speed, which means oceanic eddies exert impact on local wind field mainly through high-frequency disturbance. The Richardson number is overall greater than 0.25 (Fig. 8g, shadings in red), indicating dynamic stability in the MABL. For isolated single anticyclone eddies (ISO_ANT), almost symmetric results are shown in $\underline{\text { Fig. } 9}$ but with a positive phase and unstable boundary layer. As the classification in Table $\underline{2}$, the predecessors paid less concern to the complex combined oceanic eddies, what are their different effects on MABL? For combined doublecyclone (DBL_CYC) and double-anticyclone (DBL_ANT) eddies, the anomalous centers are also nearly in-phase and the 10-meter scalar wind anomalies are also greater than 10-meter wind speed, and it is equivalent for double-anticyclones (see Supplementary Materials Figure S5-6). Therefore, we hypothesized the synergistic local effects of combined isotropic eddies are similar with the isolated eddy. 

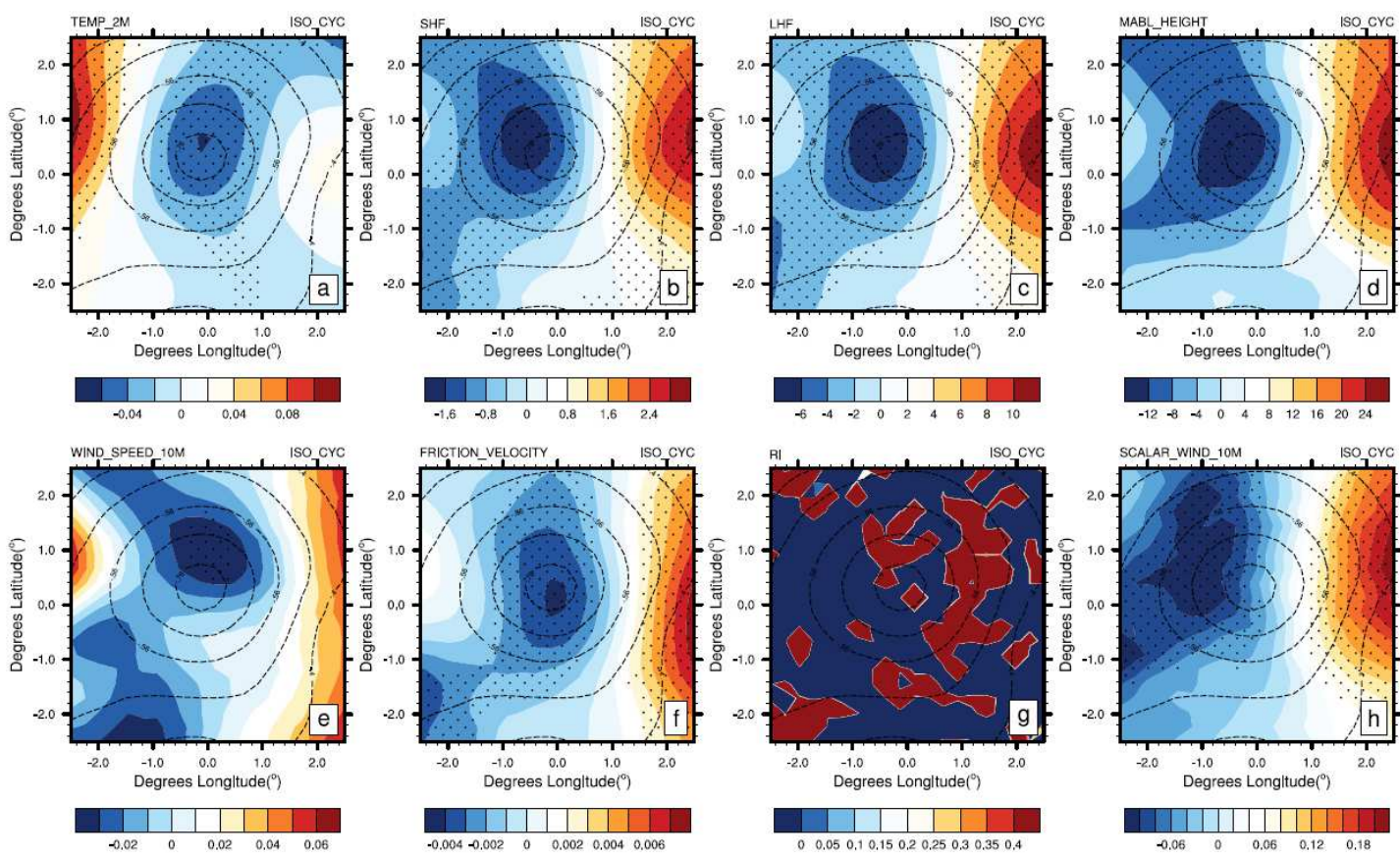

Fig 8. Composite analysis of ISO_CYC samples including SST anomaly (contours, units: ${ }^{\circ} \mathrm{C}$ ) and (a) 2-meter air temperature (shadings, units: ${ }^{\circ} \mathrm{C}$ ), (b) SHF (units: $\mathrm{W} \cdot \mathrm{m}^{-2}$ ), (c) LHF (units: $\mathrm{W} \cdot \mathrm{m}^{-2}$ ), (d) MABL height (units: $\mathrm{m}$ ), (e) 10-meter wind speed (units: $\mathrm{m} \cdot \mathrm{s}^{-1}$ ), (f) surface frictional velocity (units: $\mathrm{m} \cdot \mathrm{s}^{-1}$ ), (h) 10-meter scalar wind (units: $\mathrm{m} \cdot \mathrm{s}^{-1}$ ) anomalies and (g) the gradient Richardson number at $950 \mathrm{hPa}$. Dotted areas have passed $95 \% \mathrm{t}$-test significant level.
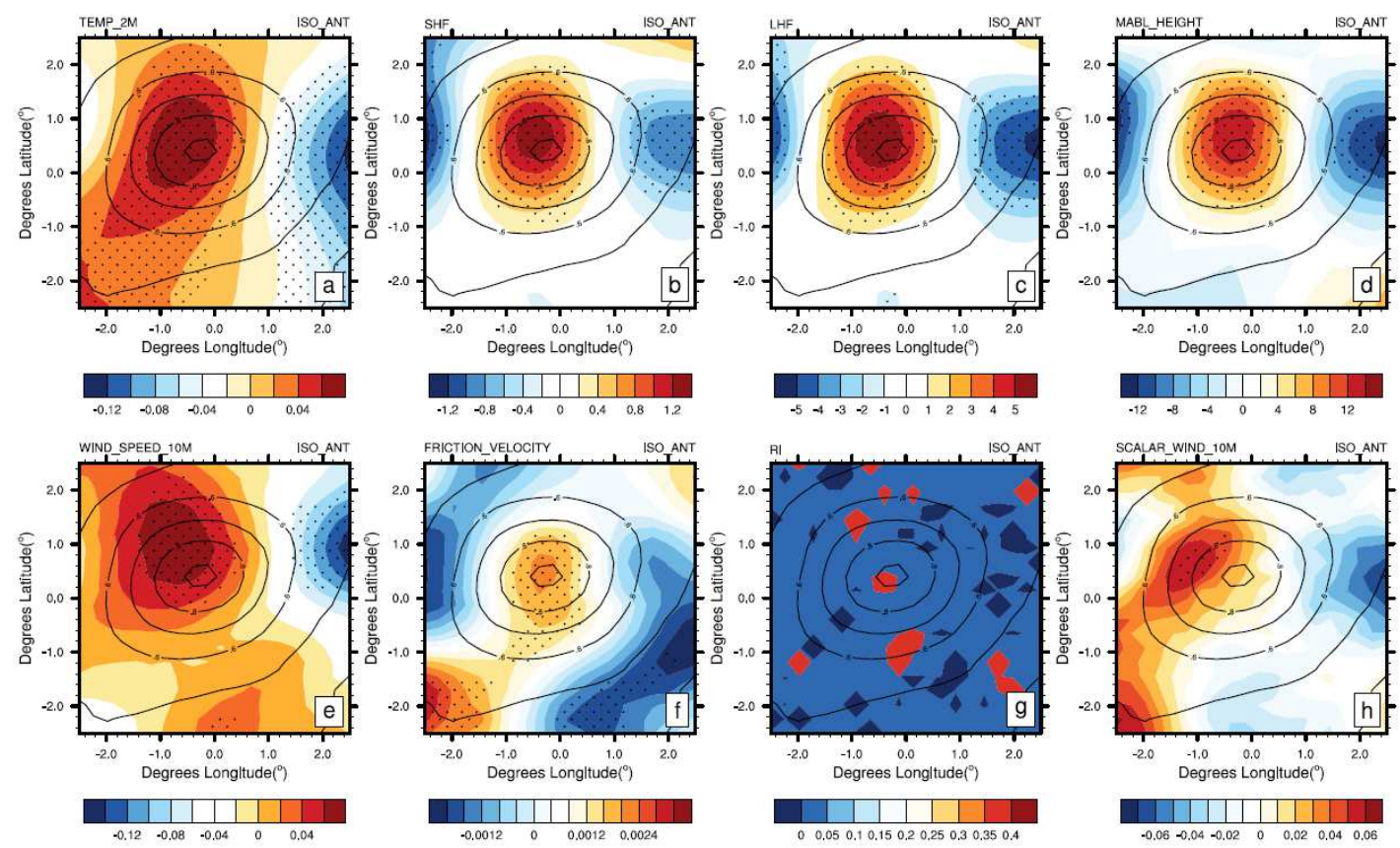

Fig 9. Composite analysis of ISO_ANT samples including SST anomaly (contour, units: ${ }^{\circ} \mathrm{C}$ ) and (a) 2-meter air temperature (shadings, units: ${ }^{\circ} \mathrm{C}$ ), (b) SHF (units: $\mathrm{W} \cdot \mathrm{m}^{-2}$ ), (c) LHF (units: $\mathrm{W} \cdot \mathrm{m}^{-2}$ ), (d) MABL height (units: $\mathrm{m}$ ), (e) 10-meter wind speed (units: $\mathrm{m} \cdot \mathrm{s}^{-1}$ ), (f) surface frictional velocity (units: $\mathrm{m} \cdot \mathrm{s}^{-1}$ ), (h) 10-meter scalar wind (units: $\mathrm{m} \cdot \mathrm{s}^{-1}$ ) anomalies and (g) the gradient Richardson number at 950hPa. Dotted areas have passed 95\% t-test significant level. 
However, the composite results are different for the PAIR eddies, as Fig. 10 shows, the 2-meter temperature, SHF, LHF, MABL height and 10meter wind speed have positive anomalous responses to the PAIR_NC_SW, which are centered at the boundary of two eddies with larger SST gradient. The situation is reversed in response to the PAIR_NW_SC since the meridional temperature gradient anomaly is negative (Fig. 11a-d). Furthermore, the 10-meter scalar wind and frictional velocity show insignificant or even repressed responses (Fig. 10 and 11). The results explained that the combined cyclone-anticyclone eddies exert effects on atmosphere mainly through the SST gradient anomalies, and the mean surface wind accelerates because of thermal wind effects instead of the intense high-frequency disturbance.

Overall, oceanic eddies are provided with warm or cool SST anomalies based on their vertical features. The thermal anomalies can heat (cool) near surface air by heat flux (usually directly SHF). The abnormal status of wind speed is the consequence of heat and momentum transporting from oceanic eddies to atmosphere. Meanwhile, this energy can also influence the MABL height. The intensity of energy exchange between anticyclone eddy and air is stronger, developing a more unstable condition for anticyclone as underlying surface, and resulting in enhancement of vertical mixing. On the contrary, the atmosphere above cyclone eddies is more stable. Thus, turbulent heat flux is undermined and 
MABL height is diminished in this situation. However, considering the oceanic eddies are not isolated in real ocean, the combined anisotropic eddies can also influence the local SST gradient thereby exert forcing on MABL via baroclinicity.
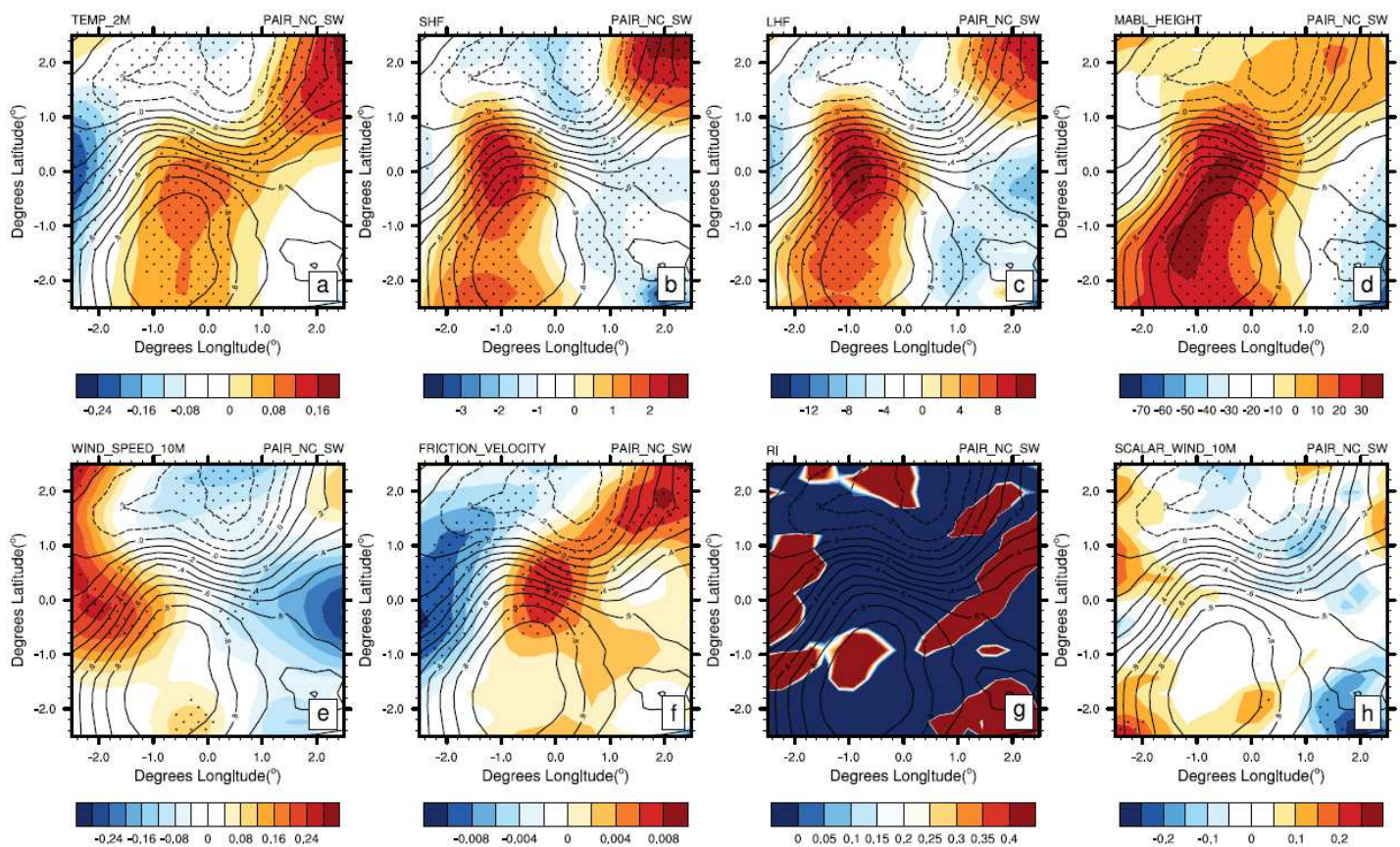

Fig 10. Composite analysis of PAIR_NC_SW samples including SST anomaly (contours, units: ${ }^{\circ} \mathrm{C}$ ) and (a) 2-meter air temperature (shadings, units: ${ }^{\circ} \mathrm{C}$ ), (b) SHF (units: $\mathrm{W} \cdot \mathrm{m}^{-2}$ ), (c) LHF (units: $\mathrm{W} \cdot \mathrm{m}^{-}$ ${ }^{2}$ ), (d) MABL height (units: $\mathrm{m}$ ), (e) 10-meter wind speed (units: $\mathrm{m} \cdot \mathrm{s}^{-1}$ ), (f) surface frictional velocity (units: $\mathrm{m} \cdot \mathrm{s}^{-1}$ ), (h) 10-meter scalar wind (units: $\mathrm{m} \cdot \mathrm{s}^{-1}$ ) anomalies and (g) the gradient Richardson number at 950hPa. Dotted areas have passed 95\% t-test significant level. 

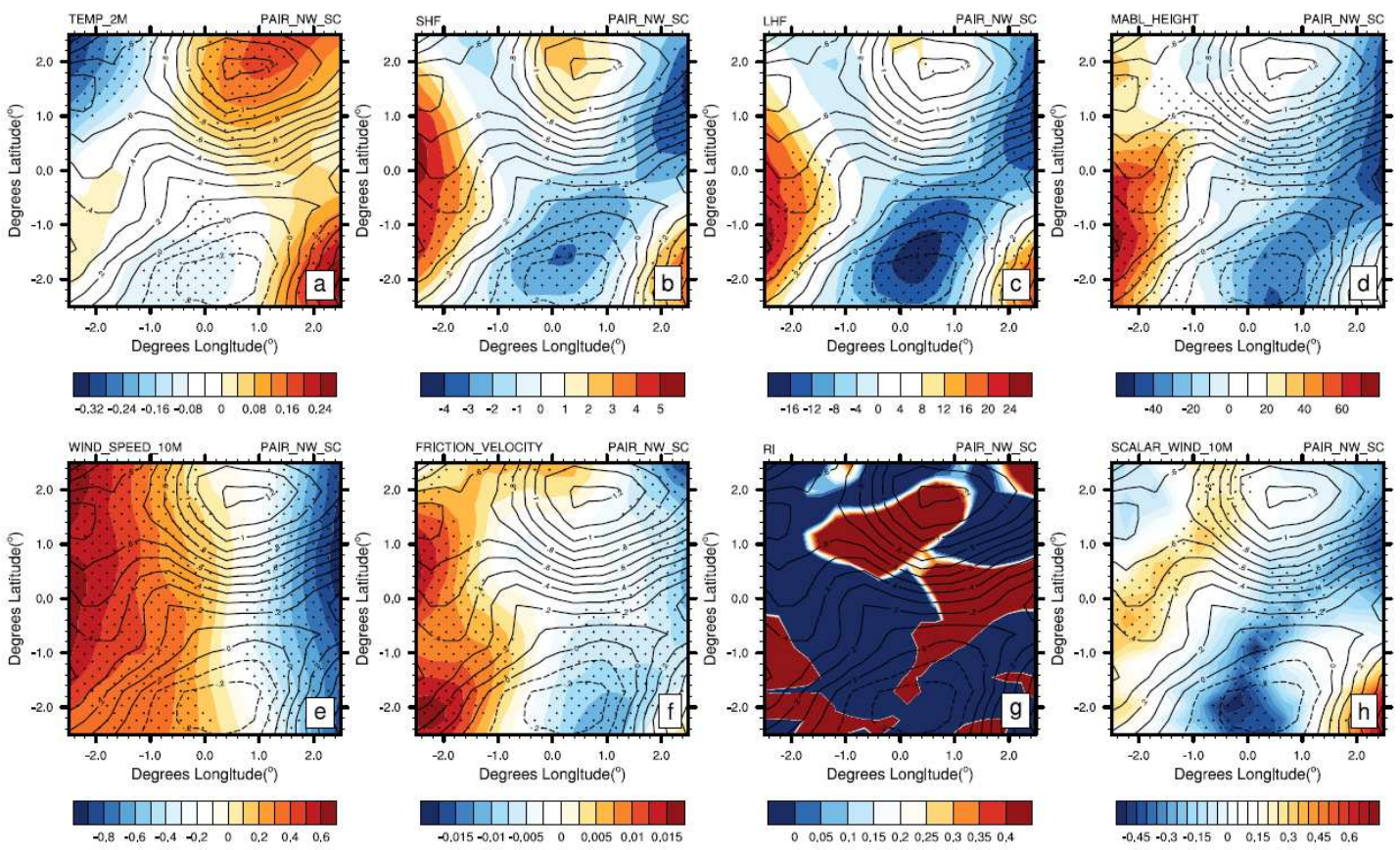

Fig 11. Composite analysis of PAIR_NW_SC samples including SST anomaly (contours, units: ${ }^{\circ} \mathrm{C}$ ) and (a) 2-meter air temperature (shadings, units: ${ }^{\circ} \mathrm{C}$ ), (b) SHF (units: $\mathrm{W} \cdot \mathrm{m}^{-2}$ ), (c) LHF (units: $\mathrm{W} \cdot \mathrm{m}^{-}$ ${ }^{2}$ ), (d) MABL height (units: $\mathrm{m}$ ), (e) 10-meter wind speed (units: $\mathrm{m} \cdot \mathrm{s}^{-1}$ ), (f) surface frictional velocity (units: $\mathrm{m} \cdot \mathrm{s}^{-1}$ ), (h) 10-meter scalar wind (units: $\mathrm{m} \cdot \mathrm{s}^{-1}$ ) anomalies and (g) the gradient Richardson number at $950 \mathrm{hPa}$. Dotted areas have passed $95 \% \mathrm{t}$-test significant level.

The above-mentioned discoveries of isolated single oceanic eddy within MABL are consistent with previous researches in other sea regions (Small et al., 2008; Ma et al., 2015a; Chen et al., 2017), yet oceanic eddies have broader influence on free atmosphere beyond MABL (Ma et al., 2015a; Zhang et al., 2019; Sun et al., 2020). Fig. 12 presents geopotential height anomalies passing 95\% t-test confidence level from MABL top (refer to Fig. 8d) up to 500hPa (Fig. 12c), and the vectors represent wind velocity at MABL top. Geopotential height anomalies are positive (negative) east to the warm (cold) positive (negative) SST centers of ISO oceanic eddies, nearly along the downwind direction at MABL top. For combined DBL, the responses are also transported to downstream locations 
but have greater absolute values. The result of PAIR indicates that the response of middle atmosphere at this time is not the dipole geopotential height anomaly induced by the dipole eddy existing form. Instead, an anticyclone-like height anomaly is produced in response to PAIR_NC_SW, i.e., an abnormal high at the downwind location of the dipole SST anomalies, whose strength is weaker than the isolated and the combined anticyclone eddies. The geopotential height anomaly distribution of middle atmosphere is consistent with the lower MABL, which is determined by the drastic SST gradient between the warm and cold eddies. The situation for PAIR_NW_SC is reversed. And, in general, geopotential height anomalies increase faster from lower to upper levels over for anticyclonic eddies than that for cyclonic eddies. 

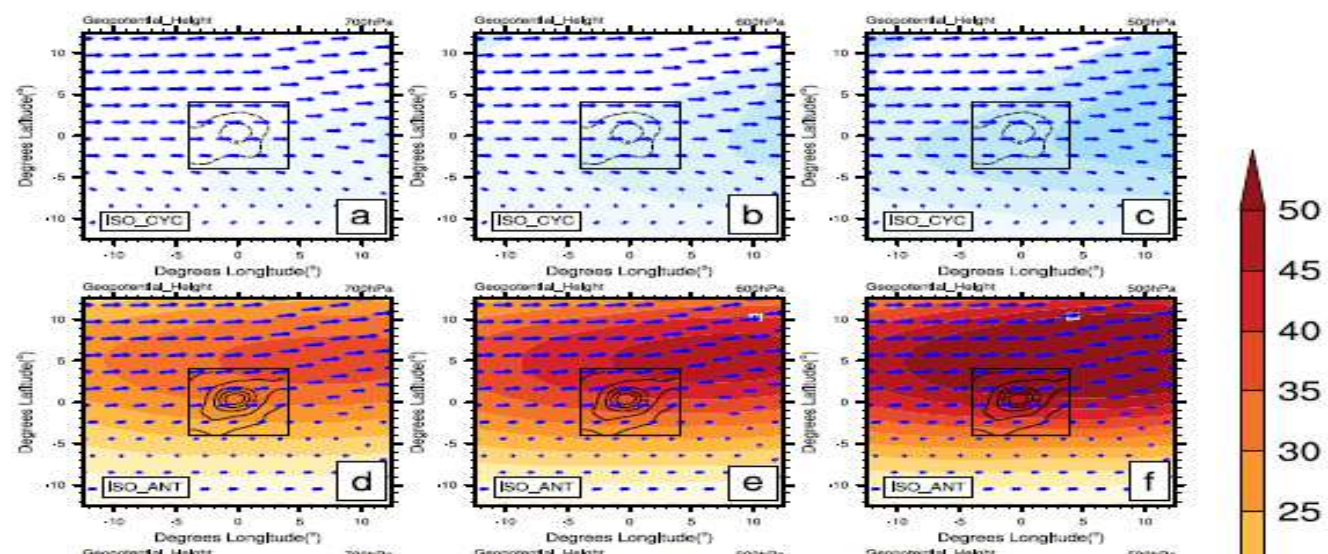

50
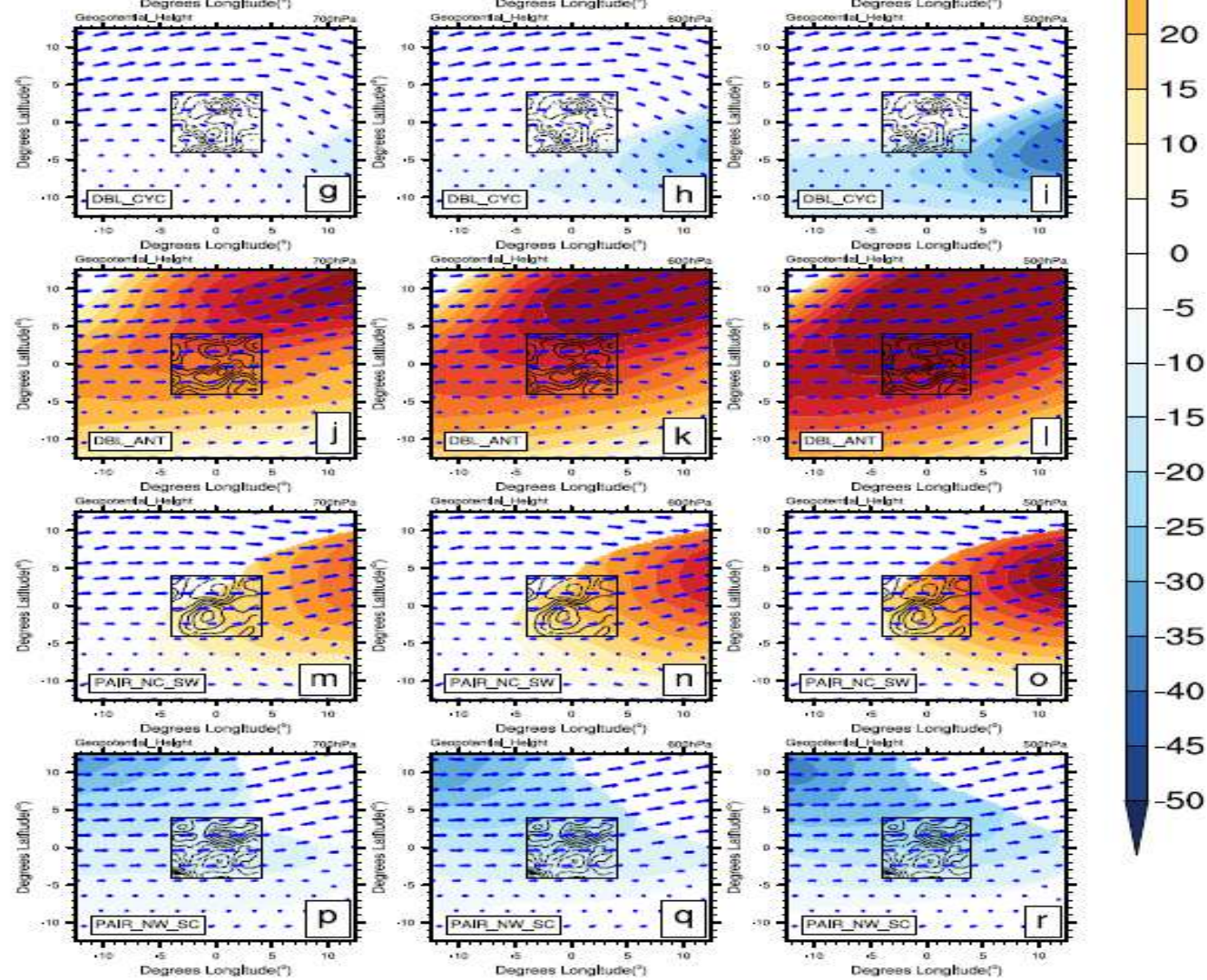

45

40

35

30

25

15

10
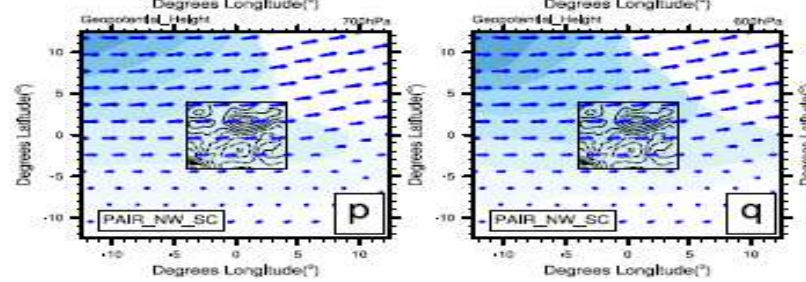

Fig 12. SST anomaly (contours, units: ${ }^{\circ} \mathrm{C}$ ) and upper atmosphere geopotential height anomalies (shadings, units: $\mathrm{m}$, passed 95\% t-test significant level) in composite analysis of (a-c) ISO_CYC (df) ISO_ANT (g-i) DBL_CYC (j-1) DBL_ANT (m-o) PAIR_NC_SW (p-r) PAIR_NW_SC at 700hPa, $600 \mathrm{hPa}$ and $500 \mathrm{hPa}$. Vectors present wind field interpolated to MABL top.

In addition to the geopotential height anomalies of the middle atmosphere caused by various oceanic eddies, we also paid attention to the differences in local convective precipitation under different existing forms of eddies (Fig. 13). The composited analysis of precipitation shows that the convective precipitation anomalies are significantly decreased over ISO 
and DBL cyclonic eddies (Fig. 13a, 13b), but not increased as much over anticyclonic eddies (Fig. 13d, 13e). Even with DBL anticyclonic eddies, the convective precipitation increment does not pass the significant test. Instead, the two ascending motions over double warm eddy centers induce a significant air descending and convective inhibition between the extremums of warm eddies (Fig. 13e). Accompanied atmospheric stability and MABL height decrement (see Supplementary Materials Figure S6) also denote the compensated descending motion. However, the PAIR_NC_SW have distinct impact on convective precipitation (ig. 13f). The convection is inhibited in the frontal area where the cold and warm eddies converge, and the promoted convection occurs where the MABL height (Fig. 11d) rises and on the warmer side of sea water. In general, oceanic eddies would affect cumulus convection above them to adjust precipitation anomalies. However, in the STFZ, a local cooling of SST caused by cyclone eddies can significantly inhibit convective process locally, but a local warming of the anticyclone eddy has the weaker effects. In summary, the ISO eddy has distinguished local forcing on MABL and free atmosphere from the combined-eddies (DBL and PAIR). The sign of the isolated eddy's vorticity determines its local forcing effects. The ISO eddy forcing effects with different polarities on the lower atmosphere are spatial unevenly distributed in the stronger and weaker years of the STFZ (cold eddies almost exist to the north in stronger years while to the south 
in weaker years), eventually resulting in the remote forcing of ISO eddies on the atmospheric upper level. The character of the DBL composite local forcing on the MABL is consistent with that of the ISO composite, but due to its dipole-center structure, the same dipole local forcing effects are caused in the MABL. Furthermore, although the intensity of the temperature anomaly center of the DBL eddy is similar with the ISO, its dipole structure caused the most significant changes in the middle atmosphere and precipitation fields among the three eddy types. This also explains that the DBL eddies have remote forcing as important as ISO eddies despite their relatively fewer cases than ISO. Finally, for the PAIR composite, its local forcing on MABL is completely different from the previous two. The changes of each physical quantity in MBAL mainly exist over the boundary of two contrary eddies. But when it comes to the middle atmosphere and precipitation field, the atmospheric responses are advected downstream by the background wind. Based on the local forcing effects, the PAIR eddies do not force the MABL that significantly when compared to the ISO eddies. However, due to the special drastic meridional temperature gradient between the two contrary eddies, the PAIR composited eddy has the most significant impact on the baroclinicity of the lower atmosphere. This is also the reason why it can cause significant remote forcing effects on the upper atmosphere in certain specific years, with the least quantity among the three types of eddies. 

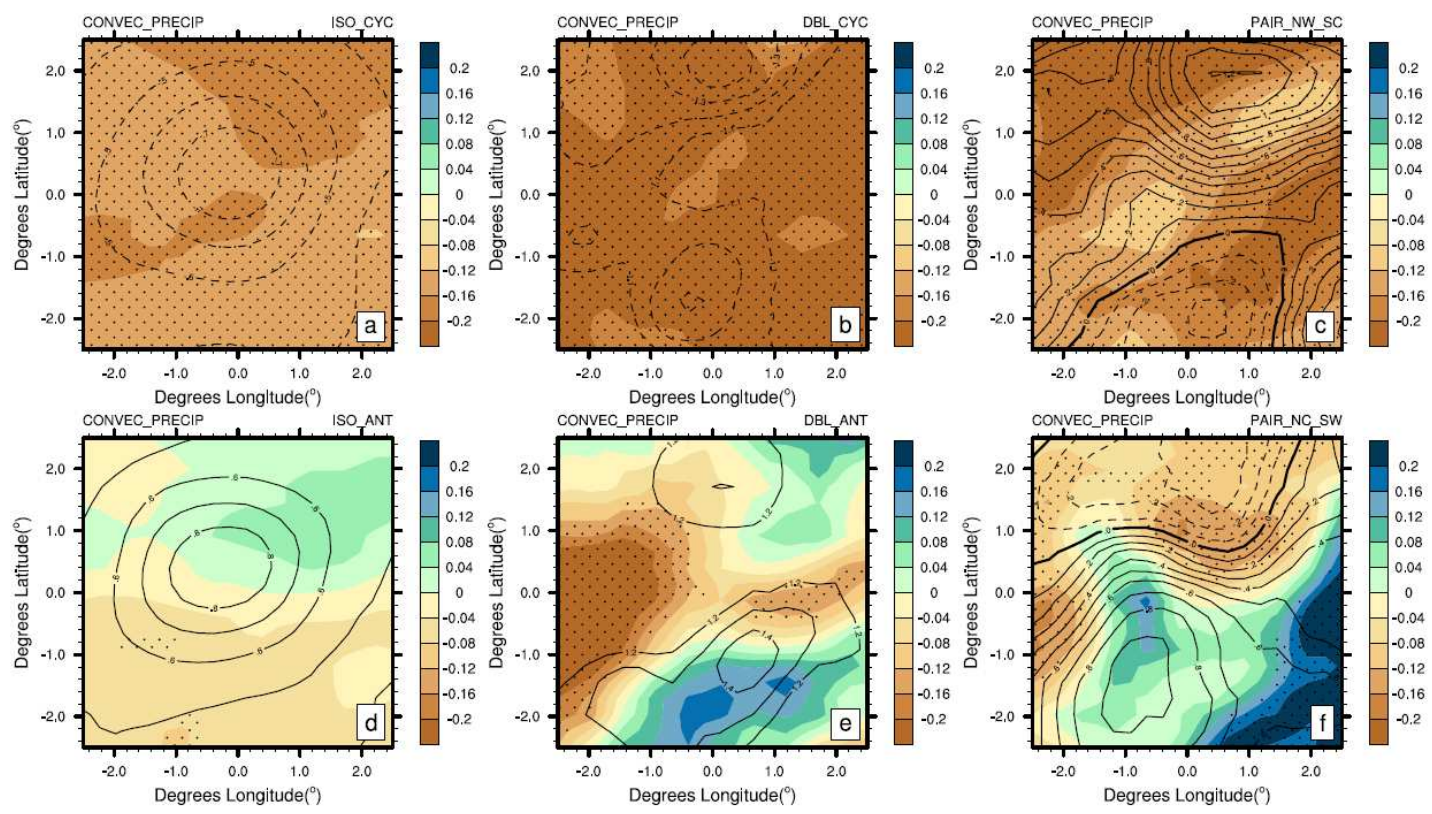

Fig 13. Composited SST anomalies (contours, units: ${ }^{\circ} \mathrm{C}$ ) of (a) ISO_CYC (b) DBL_ANT (c) PAIR_NW_SC (d) ISO_ANT (e) DBL_ANT (f) PAIR_NC_SW and composited anomalies (shadings, units: $\mathrm{kg} \cdot \mathrm{m}^{-2}$ ) of convective precipitation. Dotted areas have passed $95 \% \mathrm{t}$-test significant level.

\section{Conclusion and Discussion}

In this study, we focus on the forcing effects (Fig. 14) of the multiple oceanic eddies on mid-latitude atmosphere in wintertime North Pacific. We detected and classified the oceanic eddies into isolated single eddies (ISO), the combined double isotropic eddies (DBL) and pairs of anisotropic eddies (PAIR) types in the STFZ using CFSR dataset from 1979 to 2009 (Fig. 14a-i, ii, iii). Like previous studies (Small et al., 2008; Xu et al., 2016; Ma et al., 2015b, 2017; Sun et al., 2018), this study specifically divides the forcing effects of oceanic eddies on the upper atmosphere into local forcing on the MABL and the lower atmosphere above the eddies, and the remote 
effects on the upper atmospheric jet at the entire basin scale. Among the three types of ocean eddies in the STFZ, the ISO eddies account for $74 \%$ in total. Cyclonic (anticyclonic) ISO eddy can cause surface winds to decelerate (accelerate) and reduce (increase) latent and sensible heat fluxes, MABL height, boundary stability and disturbance locally. These local forcing effects are even transmitted upwards to the middle atmosphere and local convective precipitation fields, providing an energy basis for causing basin-scale remote forcing effect on upper atmosphere. The ISO eddies are unevenly distributed in the North Pacific basin. Furthermore, we found that more cyclone (anticyclone) ISO oceanic eddies persist to the north of the STFZ, while more anticyclone (cyclone) ISO eddies to the south in the stronger (weaker) STFZ years, which lead to the positive (negative) SST gradient, atmospheric baroclinicity and remote forcing on the interannual timescale. The local forcing of the DBL eddies on MABL depends on the numbers and properties of eddy center. In addition, DBL eddies have more significant local effects than ISO type, with the dipole structure in MABL and the more significant anomalies in the local precipitation field. It is the reason why the DBL type, with fewer cases, has remote forcing equivalent to ISO on the upper atmosphere.

The local effect in the MABL caused by the PAIR eddy, unlike the other two types, is located at the boundary of the two contrary eddies. For the MABL and middle atmosphere responses to the eddies, the PAIR type 
is weaker than the other two types. However, in the stronger (weaker) STFZ years, more north-cold and south-warm (north-warm and south-cold) types are concentrated (dispersed) on the main axis of the STFZ. The opposite sea temperature anomalies caused by each of the two eddies lead to a significant meridional temperature gradient in the STFZ region, and result in the unneglectable remote forcing although with fewer PAIR eddies. Due to the contribution of stronger (weaker) SST gradient caused by the three types of eddies in the STFZ, the STFZ intensity variations lead to the increased (decreased) upward baroclinic atmospheric energy, and finally enhance (decrease) the storm track and zonal wind at upper $300 \mathrm{hPa}$ level, which brings a link between multiple oceanic eddies and remote forcing effect on upper atmosphere (ig. 14b). Some researches (Wang et al., 2016, 2019; Chen et al., 2019b; Chen et al., 2020) have discussed the atmospheric internal adjustment considering the STFZ intensity anomaly in atmospheric simulations. We further revealed the causes of the interannual variation of the STFZ intensity in this work.

The observed interannual variation of the STFZ intensity has complex influencing factors, including large-scale sea temperature anomalies, oceanic front intensity changes, air-sea temperature difference and changes of the oceanic eddy distribution, etc. The reanalysis outputs diagnosis in this study gives a possible link and mechanism conjectures of statistically different eddy distribution and interannual variability of the 
STFZ intensity. Further research requires a series of sensitivity experiments using numerical models to distinguish the effects of the spatial distribution of numerous oceanic eddies. We have designed a series of numerical experiments to distinguish the effects of oceanic eddies and front in the North Pacific, which will be prepared for further research.

On the whole, the present study mainly focused on the existing forms and distribution features of the STFZ oceanic eddies and the corresponding local and remote effects on mid-latitude atmosphere using CFSR reanalysis outputs. On the next stage, more detailed analyses are needed using an eddy-resolved air-sea coupled numerical model. Besides, the KE also contains abundant eddy activities with extreme EKE along a latitudinal band. Ji et al. (2018) proposed a possible connection by statistically analyzing the eddy characteristics and mechanism of occurrence in the KE region: for eddies with longer durations (greater than 50 weeks), more cyclones (anticyclones) occur in the south (north) part of the Kuroshio main axis; for eddies with shorter duration (less than 20 weeks), more cyclones (anticyclones) occur in the north (south) part of the Kuroshio main axis. However, their effects on the North Pacific midlatitude atmosphere need further investigation. 
(b) Remote forcing effects

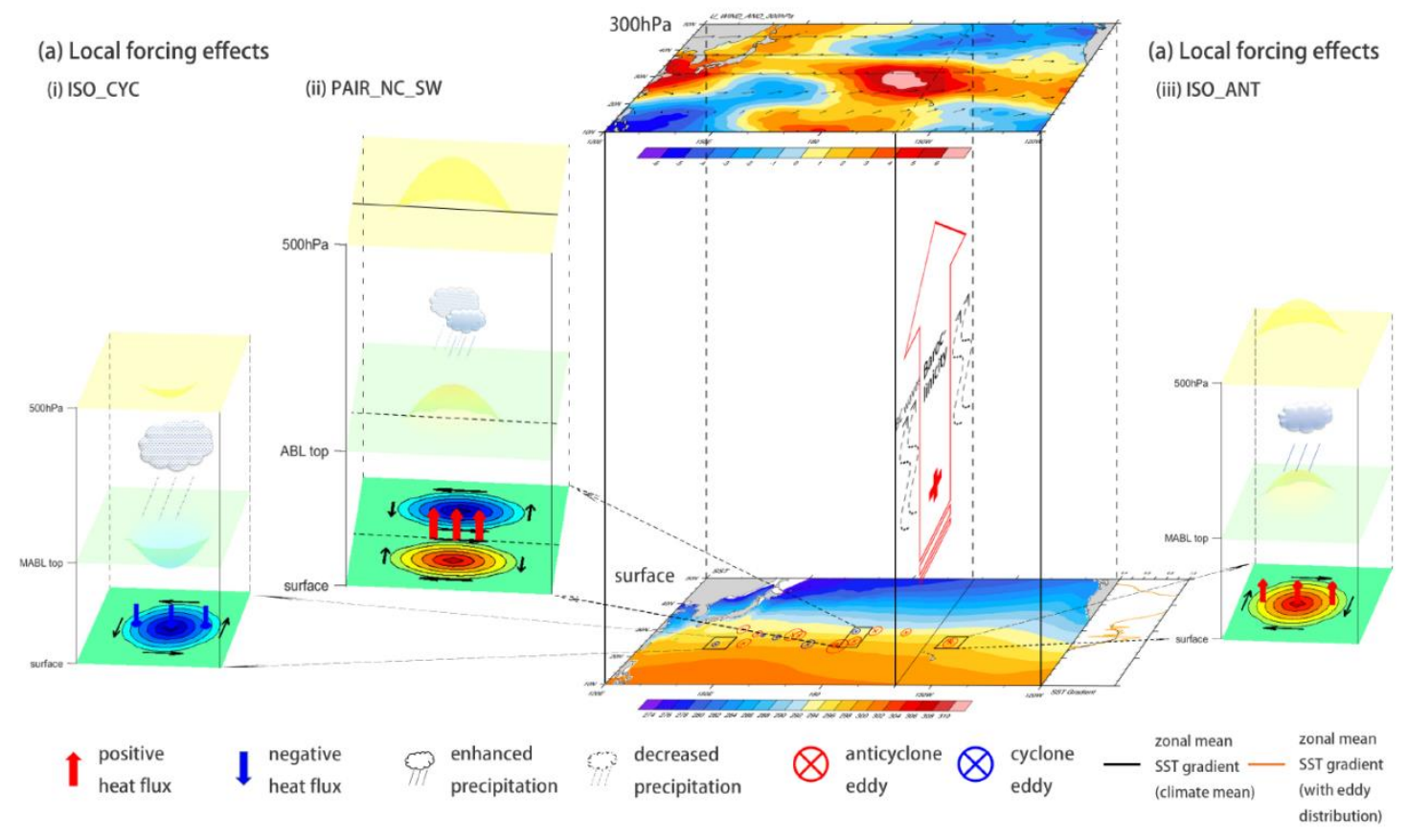

Fig 14. Schematic depiction of the (a) local and (b) remote forcing of oceanic eddies on atmosphere in the STFZ during winter. (a) surface layer presents SST anomaly and heat flux induced by eddies, responding geopotential heights are presented by the bulge of each face, and enhanced/decreased precipitation are given as icons; (b) a certain kind of eddy distribution overlays climatic SST, strengthening the STFZ intensity and affecting wind at $300 \mathrm{hPa}$. 


\section{Acknowledgements}

Haibo Hu and Yihang Zhao contribute equally as first authors. This work was supported by the National Key Program for Developing Basic Science (grants 2016YFA0600303 and 2018YFC1505900), the National Natural Science Foundation of China (grants 41330420, 41621005, 41675064, 41675067, and 41875086), the Jiangsu Province Science Foundation (Grant No. BK20201259). The authors are thankful for the support of the Jiangsu Provincial Innovation Center for Climate Change and Fundamental Research Funds for the Central University. This work was jointly supported by the Joint Open Project of KLME and CIC-FEMD (grant KLME201902). The NCEP Climate Forecast System Reanalysis 6-hourly data used in this study was obtained from the website (https://rda.ucar.edu/datasets/ds093.0/index.html\#cgibin/datasets/getWebList?

\section{Reference:}

Bai HK, Hu HB, Yang XQ, Ren XJ, Xu HM, Liu GQ (2019) Modeled MABL Responses to the Winter Kuroshio SST Front in the East China Sea and Yellow Sea. Journal of Geophysical Research-Atmospheres 124:6069-6092. https://doi.org/10.1029/2018jd029570

Bai HK, Hu HB, Perrie W, Zhang N (2020) On the characteristics and climate effects of HV-WCP events over the Kuroshio SST front during wintertime. Climate Dynamics 55: 2123-2148. https://doi.org/10.1007/s00382-020-05373-5

Carvalho D, Rocha A, Gomez-Gesteira M (2012) Ocean surface wind simulation forced by different reanalyses: Comparison with observed data along the Iberian Peninsula coast. Ocean Modelling 56:31-42. https://doi.org/10.1016/j.ocemod.2012.08.002

Chan PW (2008) Determination of Richardson number profile from remote sensing data and its aviation application. In: Mann J et al. (eds) 14th International Symposium for the Advancement of Boundary Layer Remote Sensing, vol 1. IOP Conference Series Earth and Environmental Science. pp U352-U359. https://doi.org/10.1088/1755-1307/1/1/012043

Chelton DB et al. (2001) Observations of coupling between surface wind stress and sea surface temperature in the eastern tropical Pacific. Journal of Climate 14:1479-1498. https://doi.org/10.1175/1520-0442(2001)014<1479:Oocbsw>2.0.Co;2

Chelton DB, Schlax MG, Samelson RM, de Szoeke RA (2007) Global observations of large oceanic eddies. Geophysical Research Letters 34. https://doi.org/10.1029/2007gl030812

Chelton DB, Schlax MG, Samelson RM (2011) Global observations of nonlinear mesoscale eddies. Progress in Oceanography 91:167-216. https://doi.org/10.1016/j.pocean.2011.01.002

Chen CL, Wang GH, Xie SP, Liu W (2019a) Why Does Global Warming Weaken the Gulf Stream but Intensify the Kuroshio?. Journal of Climate 32:7437-7451. https://doi.org/10.1175/jcli-d18-0895.1

Chen FF, Chen QY, Hu HB, Fang JB, Bai HK (2020) Synergistic Effects of Midlatitude Atmospheric Upstream Disturbances and Oceanic Subtropical Front Intensity Variability on Western Pacific Jet Stream in Winter. Journal of Geophysical Research: Atmospheres 125. https://doi.org/10.1029/2020JD032788

Chen LJ, Jia YL, Liu QY (2017) Oceanic eddy-driven atmospheric secondary circulation in the winter Kuroshio Extension region. Journal of Oceanography 73:295-307. https://doi.org/10.1007/s10872-016-0403-z 
Chen QY, Hu HB, Ren XJ, Yang XQ (2019b) Numerical Simulation of Midlatitude Upper-Level Zonal Wind Response to the Change of North Pacific Subtropical Front Strength. Journal of Geophysical Research-Atmospheres 124:4891-4912. https://doi.org/10.1029/2018jd029589

Duchon CE (1979) Lanczos filtering in one and two dimensions. Journal of Applied Meteorology and Climatology 18(8): 1016-1022. https://doi.org/10.1175/15200450(1979)018<1016:LFIOAT>2.0.CO;2

Deser C, Timlin MS (1997) Atmosphere-ocean interaction on weekly timescales in the North Atlantic and Pacific. Journal of Climate 10:393-408. https://doi.org/10.1175/15200442(1997)010<0393:Aoiowt $>2.0 . \mathrm{Co} ; 2$

Di Lorenzo E, Schneider N, Cobb KM, Franks PJS, Chhak K, Miller AJ, Rivière P (2008) North Pacific Gyre Oscillation links ocean climate and ecosystem change. Geophysical Research Letters 35: L08607. https://doi.org/10.1029/2007GL032838

Fairall CW, Bradley EF, Rogers DP, Edson JB, Young GS (1996) Bulk parameterization of air-sea fluxes for Tropical Ocean Global Atmosphere Coupled Ocean Atmosphere Response Experiment. Journal of Geophysical Research-Oceans 101:3747-3764. https://doi.org/10.1029/95jc03205

Foussard A, Lapeyre G, Plougonven R (2019) Storm Track Response to Oceanic Eddies in Idealized Atmospheric Simulations. Journal of Climate 32:445-463. https://doi.org/10.1175/jcli-d-180415.1

Ji JL et al. (2018) Oceanic Eddy Characteristics and Generation Mechanisms in the Kuroshio Extension Region. Journal of Geophysical Research-Oceans 123:8548-8567. https://doi.org/10.1029/2018jc014196

Kobashi F, Xie SP, Iwasaka N, Sakamoto TT (2008) Deep Atmospheric Response to the North Pacific Oceanic Subtropical Front in Spring. Journal of Climate 21:5960-5975. https://doi.org/10.1175/2008jcli2311.1

Ma J, Xu HM, Dong CM, Lin PF, Liu Y (2015a) Atmospheric responses to oceanic eddies in the Kuroshio Extension region. Journal of Geophysical Research-Atmospheres 120:6313-6330. https://doi.org/10.1002/2014jd022930

Ma XH et al. (2015b) Distant Influence of Kuroshio Eddies on North Pacific Weather Patterns? Scientific Reports 5. https://doi.org/10.1038/srep17785

Ma XH et al. (2017) Importance of Resolving Kuroshio Front and Eddy Influence in Simulating the North Pacific Storm Track. Journal of Climate 30:1861-1880. https://doi.org/10.1175/jcli-d16-0154.1

Mafimbo AJ, Reason CJC (2010) Air-sea interaction over the upwelling region of the Somali coast. Journal of Geophysical Research-Oceans 115. https://doi.org/10.1029/2009jc005439

Mantua NJ, Hare SR (2002) The Pacific decadal oscillation. Journal of Oceanography 58:35-44. https://doi.org/10.1023/a:1015820616384

Mantua NJ, Hare SR, Zhang Y, Wallace JM, Francis RC (1997) A Pacific interdecadal climate oscillation with impacts on salmon production. Bulletin of the American Meteorological Society 78:1069-1079. https://doi.org/10.1175/1520-0477(1997)078<1069:Apicow $>2.0$.Co;2

Miller AJ, Schneider N (2000) Interdecadal climate regime dynamics in the North Pacific Ocean: theories, observations and ecosystem impacts. Progress in Oceanography 47:355-379. https://doi.org/10.1016/s0079-6611(00)00044-6 
Minobe S, Kuwano-Yoshida A, Komori N, Xie SP, Small RJ (2008) Influence of the Gulf Stream on the troposphere. Nature 452:206-U251. https://doi.org/10.1038/nature06690

Nakamura H, Lin G, Yamagata T (1997) Decadal climate variability in the North Pacific during the recent decades. Bulletin of the American Meteorological Society 78:2215-2225. https://doi.org/10.1175/1520-0477(1997)078<2215:Dcvitn>2.0.Co;2

Nakamura H, Sampe T, Tanimoto Y, Shimpo A (2004) Observed associations among storm tracks, jet streams and midlatitude oceanic fronts. In: Wang C, Xie SP, Carton JA (eds) Earth's Climate: The Ocean-Atmosphere Interaction, vol 147. Geophysical Monograph Book Series. pp 329345. https://doi.org/10.1029/147GM18

Nakamura M, Yamane S (2010) Dominant Anomaly Patterns in the Near-Surface Baroclinicity and Accompanying Anomalies in the Atmosphere and Oceans. Part II: North Pacific Basin. Journal of Climate 23:6445-6467. https://doi.org/10.1175/2010jcli3017.1

Namias J (1969) SEASONAL INTERACTIONS BETWEEN NORTH PACIFIC OCEAN AND ATMOSPHERE DURING 1960S. Monthly Weather Review 97:173-192. https://doi.org/10.1175/1520-0493(1969)097<0173:Sibtnp>2.3.Co;2

Nencioli F, Dong CM, Dickey T, Washburn L, McWilliams JC (2010) A Vector Geometry-Based Eddy Detection Algorithm and Its Application to a High-Resolution Numerical Model Product and High-Frequency Radar Surface Velocities in the Southern California Bight. Journal of Atmospheric and Oceanic Technology 27:564-579. https://doi.org/10.1175/2009jtecho725.1

Nonaka M, Xie SP (2003) Covariations of sea surface temperature and wind over the Kuroshio and its extension: Evidence for ocean-to-atmosphere feedback. Journal of Climate 16:1404-1413. https://doi.org/10.1175/1520-0442(2003)16<1404:Cossta $>2.0 . C o ; 2$

O'Neill LW, Chelton DB, Esbensen SK (2003) Observations of SST-induced perturbations of the wind stress field over the Southern Ocean on seasonal timescales. Journal of Climate 16:23402354. https://doi.org/10.1175/2780.1

Palmer TN, Zhaobo S (1985) A MODELING AND OBSERVATIONAL STUDY OF THE RELATIONSHIP BETWEEN SEA-SURFACE TEMPERATURE IN THE NORTHWEST ATLANTIC AND THE ATMOSPHERIC GENERAL-CIRCULATION. Quarterly Journal of the Royal Meteorological Society 111:947-975. https://doi.org/10.1256/smsqj.47002

Qiu B (1999) Seasonal eddy field modulation of the North Pacific subtropical countercurrent: TOPEX/Poseidon observations and theory. Journal of Physical Oceanography 29:2471-2486. https://doi.org/10.1175/1520-0485(1999)029<2471:Sefmot>2.0.Co;2

Qiu B, Chen SM (2010) Interannual Variability of the North Pacific Subtropical Countercurrent and Its Associated Mesoscale Eddy Field. Journal of Physical Oceanography 40:213-225. https://doi.org/10.1175/2009jpo4285.1

Roden GI (1975) NORTH PACIFIC TEMPERATURE, SALINITY, SOUND-VELOCITY AND DENSITY FRONTS AND THEIR RELATION TO WIND AND ENERGY FLUX FIELDS. Journal of Physical Oceanography 5:557-571. https://doi.org/10.1175/15200485(1975)005<0557:Onptss $>2.0$.Co;2

Russell DR (2006) Development of a time-domain, variable-period surface-wave magnitude measurement procedure for application at regional and teleseismic distances, part I: Theory. Bulletin of the Seismological Society of America 96(2): 665-677. https://doi.org/10.1785/0120050055 
Small RJ et al. (2008) Air-sea interaction over ocean fronts and eddies. Dynamics of Atmospheres and Oceans 45:274-319. https://doi.org/10.1016/j.dynatmoce.2008.01.001

Small RJ, Tomas RA, Bryan FO (2014) Storm track response to ocean fronts in a global highresolution climate model. Climate Dynamics 43:805-828. https://doi.org/10.1007/s00382-0131980-9

Small RJ, Xie SP, Hafner J (2005) Satellite observations of mesoscale ocean features and copropagating atmospheric surface fields in the tropical belt. Journal of Geophysical ResearchOceans 110. https://doi.org/10.1029/2004jc002598

Sun JX, Zhang SP, Nowotarski CJ, Jiang YX (2020) Atmospheric Responses to Mesoscale Oceanic Eddies in the Winter and Summer North Pacific Subtropical Countercurrent Region. Atmosphere 11. https://doi.org/10.3390/atmos11080816

Sun XG, Tao LF, Yang XQ (2018) The Influence of Oceanic Stochastic Forcing on the Atmospheric Response to Midlatitude North Pacific SST Anomalies. Geophysical Research Letters 45:9297-9304. https://doi.org/10.1029/2018g1078860

Tokinaga H, Tanimoto Y, Xie SP, Sampe T, Tomita H, Ichikawa H (2009) Ocean Frontal Effects on the Vertical Development of Clouds over the Western North Pacific: In Situ and Satellite Observations. Journal of Climate 22:4241-4260. https://doi.org/10.1175/2009jcli2763.1

Uda M, Hasunuma K (1969) The eastward subtropical countercurrent in the western North Pacific Ocean. Journal of the Oceanographical Society of Japan 25(4): 201-210. https://doi.org/10.5928/kaiyou1942.25.201

Vecchi GA, Xie SP, Fischer AS (2004) Ocean-atmosphere covariability in the western Arabian Sea. Journal of Climate 17:1213-1224. https://doi.org/10.1175/15200442(2004)017<1213:Ocitwa $>2.0 . \mathrm{Co} ; 2$

Wang LY, Hu HB, Yang XQ (2019) The atmospheric responses to the intensity variability of subtropical front in the wintertime North Pacific. Climate Dynamics 52:5623-5639. https://doi.org/10.1007/s00382-018-4468-9

Wang LY, Hu HB, Yang XQ, Ren XJ (2016) Atmospheric eddy anomalies associated with the wintertime North Pacific subtropical front strength and their influences on the seasonal-mean atmosphere. Science China-Earth Sciences 59:2022-2036. https://doi.org/10.1007/s11430016-5331-7

Wen ZB, Hu HB, Song ZY, Bai HK, Wang ZY (2020) Different Influences of Mesoscale Oceanic Eddies on the North Pacific Subsurface Low Potential Vorticity Water Mass Between Winter and Summer. Journal of Geophysical Research-Oceans 125. https://doi.org/10.1029/2019jc015333

Xie SP (2004) Satellite observations of cool ocean-atmosphere interaction. Bulletin of the American Meteorological Society 85:195-208. https://doi.org/10.1175/bams-85-2-195

Xu LX, Li PL, Xie SP, Liu QY, Liu C, Gao WD (2016) Observing mesoscale eddy effects on modewater subduction and transport in the North Pacific. Nature Communications 7. https://doi.org/10.1038/ncomms10505

Xue Y, Huang BY, Hu ZZ, Kumar A, Wen CH, Behringer D, Nadiga S (2011) An assessment of oceanic variability in the NCEP climate forecast system reanalysis. Climate Dynamics 37:2511-2539. https://doi.org/10.1007/s00382-010-0954-4

Yoshida K, Kidokoro T (1967) A Subtropical Counter-Curreut in the North Pacific. Journal of the Oceanographical Society of Japan 23(2): 88-91. https://doi.org/10.5928/kaiyou1942.23.88 
Zhang XZ, Ma XH, Wu LX (2019) Effect of Mesoscale Oceanic Eddies on Extratropical Cyclogenesis: A Tracking Approach. Journal of Geophysical Research-Atmospheres 124:6411-6422. https://doi.org/10.1029/2019jd030595 
Figure captions:

Fig 1. Filtered sea surface EKE (shadings, units: $\mathrm{m}^{2} \mathrm{~s}^{-2}$, a: 300-day high-pass; b: 3-7 day bandpass) with averaged meridional sea temperature gradient (contours, $-\partial \mathrm{T} / \partial \mathrm{y}$, units: ${ }^{\circ} \mathrm{C} /{ }^{\circ}$, a: surface; b: 105m depth) and current velocity (vectors, a: surface; b: 105m depth) in DJF from 1979 to 2009. The STFZ region is outlined by the black box. Attached solid lines are zonal mean of corresponding filtered EKE (X bottom axis, units: $10^{-4} \cdot \mathrm{m}^{2} \mathrm{~s}^{-2}$, color: orange) and zonal mean of corresponding meridional temperature gradient from $140^{\circ} \mathrm{E}$ to $140^{\circ} \mathrm{W}$ (X top axis, units: ${ }^{\circ} \mathrm{C} /{ }^{\circ}$; color: black).

Fig 2. Standardized time series of the ITS (black), EKE (orange) index and U-component of STCC index (blue). The ITS, EKE index, and U-component of STCC index are the spatial average of the SST gradient in $24^{\circ} \mathrm{N}-32^{\circ} \mathrm{N} \& 140^{\circ} \mathrm{E}-140^{\circ} \mathrm{W}, 3-7$ days bandpass filtered sea surface EKE in the eddy locations within STFZ, and u-component of current at sea surface in $18^{\circ} \mathrm{N}-24^{\circ} \mathrm{N} \& 140^{\circ} \mathrm{E}-$ $157^{\circ} \mathrm{W}$, respectively. The reference lines are $\pm \sigma$. X-axis presents the years; Y-axis presents the standardized indexes.

Fig 3. Difference of averaged (a) SHF (units: $\mathrm{W} \cdot \mathrm{m}^{-2}$ ), (b) LHF (units: $\mathrm{W} \cdot \mathrm{m}^{-2}$ ), (c) Eady growth rate (units: $10^{-5} \mathrm{~m} \cdot \mathrm{s}^{-2}$ ), (d) storm track at $300 \mathrm{hPa}$ (units: $\mathrm{m}^{2} \mathrm{~s}^{-2}$ ), (e) u-component of wind at $300 \mathrm{hPa}$ (units: $\mathrm{m} \cdot \mathrm{s}^{-1}$ ) between stronger and weaker years of the STFZ. The STFZ region is outlined by the black box. Dotted areas have passed 95\% t-test significant level.

Fig 4. Comparison of eddy occurrences in stronger (a-e) and weaker (f-j) of STFZ intensity years. Blue (Red) marker represents cyclone (anticyclone) eddies. Meridional SST gradient anomaly (shadings, units: ${ }^{\circ} \mathrm{C} /{ }^{\circ}$ ) and averaged current velocity (vector, units: $\mathrm{m} \cdot \mathrm{s}^{-1}$ ) from surface to $205 \mathrm{~m}$ of the year are also given in pictures. (a1-j1) present zonal means of meridional SST gradient, black solid line is average from all 31 years, red or blue line is average of the stronger or weaker STFZ year; (a2-j2) present zonal means of current u-component from $140^{\circ} \mathrm{E}$ to $157^{\circ} \mathrm{W}$, black solid line is the average value of all 31 years, green line is the value of the respective year.

Fig 5. Comparison of eddy occurrence in stronger (a-e) and weaker ( $\mathrm{f}-\mathrm{j})$ years. Meridional SST gradient anomaly (Shadings, units: ${ }^{\circ} \mathrm{C} /{ }^{\circ}$ ) are masked out in eddy positions. (a1-j1) present zonal means of meridional SST gradient from $140^{\circ} \mathrm{E}$ to $140^{\circ} \mathrm{W}$, black solid line is average from all 31 years, red and blue lines are average of the stronger or weaker STFZ year. (a2-j2) present zonal means of meridional SST gradient anomaly caused by the ISO eddies (black), the DBL (green) and the PAIR (purple) eddies. The cell-shading ones are the positions of DBL (green) and PAIR (purple) eddies. The ones with normal shadings are ISO eddies.

Fig 6. Spatial distribution and ratio of eddies in (a) stronger, (b) normal, and (c) weaker years of the STFZ. For all eddies in 31 years, $16.1 \%$ eddies occur in stronger STFZ years; $60.9 \%$ and $23.0 \%$ for normal and weaker years, respectively. Obviously, most cyclone eddies occur north (south) to $28^{\circ}$ $\mathrm{N}$ with $70.2 \%(68.2 \%)$ of total cyclones in the stronger (weaker) STFZ intensity years, while anticyclone eddies occur north (south) to $28^{\circ} \mathrm{N}$ with $60.0 \%(54.3 \%)$ in the weaker (stronger) years.

Fig 7. Spatial distribution and ratio of eddies in (a, d, g) stronger, (b, e, h) normal, and (c, f, i) weaker years of the STFZ. (a-c) for ISO, (d-f) for DBL and (g-i) for PAIR eddies. ISO eddies perform almost the same as that in Fig. 6, and more significant percentage characteristics appear for DBL eddies. For the PAIR eddies, longitudinal cyclone-anticyclone pairs (cold to the north and warm to the south) are presented with orange markers of (g-i) and longitudinal anticyclone-cyclone pairs (warm to the north and cold to the south) are presented with green markers of (g-i).

Fig 8. Composite analysis of ISO_CYC samples including SST anomaly (contours, units: ${ }^{\circ} \mathrm{C}$ ) and (a) 2-meter air temperature (shadings, units: ${ }^{\circ} \mathrm{C}$ ), (b) SHF (units: $\mathrm{W} \cdot \mathrm{m}^{-2}$ ), (c) LHF (units: $\mathrm{W} \cdot \mathrm{m}^{-2}$ ), 
(d) MABL height (units: m), (e) 10-meter wind speed (units: $\mathrm{m} \cdot \mathrm{s}^{-1}$ ), (f) surface frictional velocity (units: $\mathrm{m} \cdot \mathrm{s}^{-1}$ ), (h) 10-meter scalar wind (units: $\mathrm{m} \cdot \mathrm{s}^{-1}$ ) anomalies and $(\mathrm{g})$ the gradient Richardson number at $950 \mathrm{hPa}$. Dotted areas have passed $95 \% \mathrm{t}$-test significant level.

Fig 9. Composite analysis of ISO_ANT samples including SST anomaly (contour, units: ${ }^{\circ} \mathrm{C}$ ) and (a) 2-meter air temperature (shadings, units: ${ }^{\circ} \mathrm{C}$ ), (b) SHF (units: $\mathrm{W} \cdot \mathrm{m}^{-2}$ ), (c) LHF (units: $\mathrm{W} \cdot \mathrm{m}^{-2}$ ), (d) MABL height (units: $\mathrm{m}$ ), (e) 10-meter wind speed (units: $\mathrm{m}^{-\mathrm{s}^{-1}}$ ), (f) surface frictional velocity (units: $\mathrm{m} \cdot \mathrm{s}^{-1}$ ), (h) 10-meter scalar wind (units: $\mathrm{m} \cdot \mathrm{s}^{-1}$ ) anomalies and $(\mathrm{g}$ ) the gradient Richardson number at 950hPa. Dotted areas have passed 95\% t-test significant level.

Fig 10. Composite analysis of PAIR_NC_SW samples including SST anomaly (contour, units: ${ }^{\circ} \mathrm{C}$ ) and (a) 2-meter air temperature (shadings, units: ${ }^{\circ} \mathrm{C}$ ), (b) SHF (units: $\mathrm{W} \cdot \mathrm{m}^{-2}$ ), (c) LHF (units: $\mathrm{W} \cdot \mathrm{m}^{-}$ ${ }^{2}$ ), (d) MABL height (units: $\mathrm{m}$ ), (e) 10-meter wind speed (units: $\mathrm{m} \cdot \mathrm{s}^{-1}$ ), (f) surface frictional velocity (units: $\mathrm{m} \cdot \mathrm{s}^{-1}$ ), (h) 10-meter scalar wind (units: $\mathrm{m} \cdot \mathrm{s}^{-1}$ ) anomalies and (g) the gradient Richardson number at $950 \mathrm{hPa}$. Dotted areas have passed $95 \% \mathrm{t}$-test significant level.

Fig 11. Composite analysis of PAIR_NW_SC samples including SST anomaly (contour, units: ${ }^{\circ} \mathrm{C}$ ) and (a) 2-meter air temperature (shadings, units: ${ }^{\circ} \mathrm{C}$ ), (b) SHF (units: $\mathrm{W} \cdot \mathrm{m}^{-2}$ ), (c) LHF (units: $\mathrm{W} \cdot \mathrm{m}^{-}$ ${ }^{2}$ ), (d) MABL height (units: $\mathrm{m}$ ), (e) 10-meter wind speed (units: $\mathrm{m} \cdot \mathrm{s}^{-1}$ ), (f) surface frictional velocity (units: $\mathrm{m} \cdot \mathrm{s}^{-1}$ ), (h) 10-meter scalar wind (units: $\mathrm{m} \cdot \mathrm{s}^{-1}$ ) anomalies and (g) the gradient Richardson number at $950 \mathrm{hPa}$. Dotted areas have passed $95 \% \mathrm{t}$-test significant level.

Fig 12. SST anomaly (contours, units: ${ }^{\circ} \mathrm{C}$ ) and upper atmosphere geopotential height anomalies (shadings, units: $\mathrm{m}$, passed $95 \% \mathrm{t}$-test significant level) in composite analysis of (a-c) ISO_CYC (df) ISO_ANT (g-i) DBL_CYC (j-1) DBL_ANT (m-o) PAIR_NC_SW (p-r) PAIR_NW_SC at 700hPa, $600 \mathrm{hPa}$ and $500 \mathrm{hPa}$. Vectors present wind field interpolated to MABL top.

Fig 13. Composited SST anomalies (contours, units: ${ }^{\circ} \mathrm{C}$ ) of (a) ISO_CYC (b) DBL_ANT (c) PAIR_NW_SC (d) ISO_ANT (e) DBL_ANT (f) PAIR_NC_SW and composited anomalies (shadings, units: $\mathrm{kg} \cdot \mathrm{m}^{-2}$ ) of convective precipitation. Dotted areas have passed $95 \% \mathrm{t}$-test significant level.

Fig 14. Schematic depiction of the (a) local and (b) remote forcing of oceanic eddies on atmosphere in the STFZ during winter. (a) surface layer presents SST anomaly and heat flux induced by eddies, responding geopotential heights are presented by the bulge of each face, and enhanced/decreased precipitation are given as icons; (b) a certain kind of eddy distribution overlays climatic SST, strengthening the STFZ intensity and affecting wind at 300hPa.

Table captions:

Table 1. Eddy Groups

Table 2. The Numbers of Different Eddy Events 


\section{Figures}

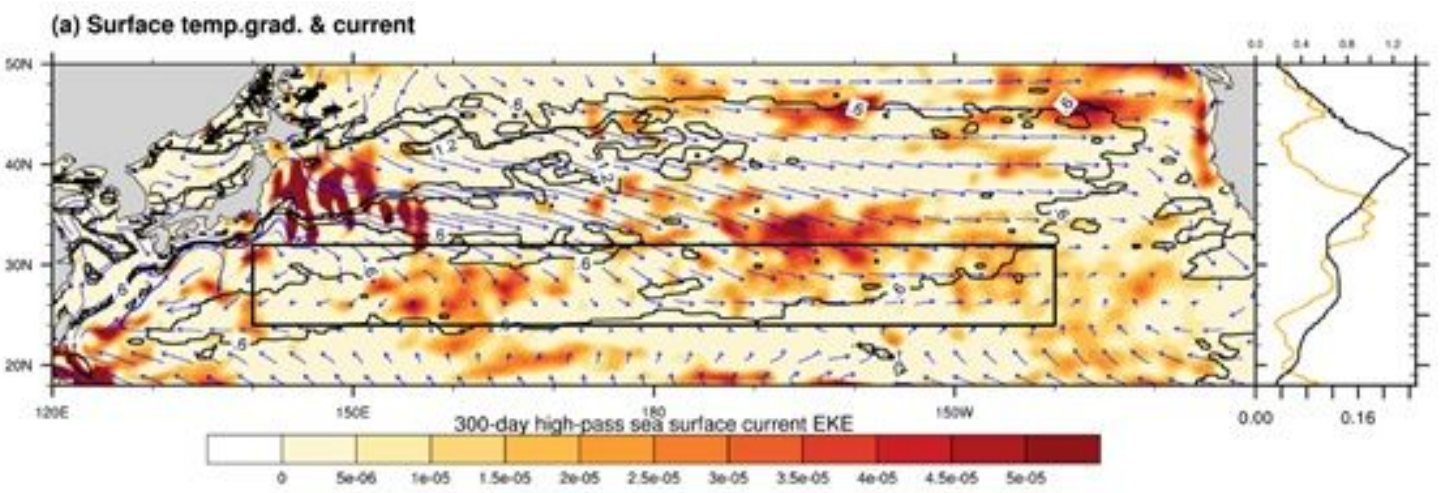

(b) Subsurface temp.grad. \& current

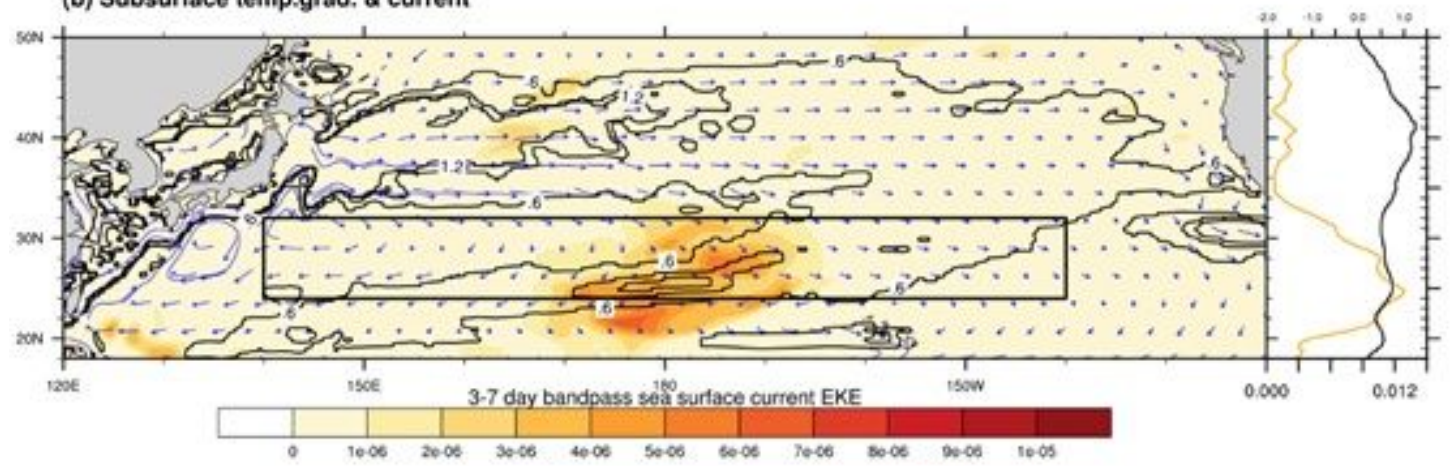

Figure 1

Filtered sea surface EKE (shadings, units: m2s-2, a: 300-day high-pass; b: 3-7 day bandpass) with averaged meridional sea temperature gradient (contours, $-\partial \mathrm{T} / \partial \mathrm{y}$, units: $\varangle /^{\circ}$, a: surface; b: $105 \mathrm{~m}$ depth) and current velocity (vectors, a: surface; b: 105m depth) in DJF from 1979 to 2009 . The STFZ region is outlined by the black box. Attached solid lines are zonal mean of corresponding filtered EKE ( $\mathrm{X}$ bottom axis, units: $10-4 \cdot \mathrm{m} 2 \mathrm{~s}-2$, color: orange) and zonal mean of corresponding meridional temperature gradient from $140^{\circ} \mathrm{E}$ to $140^{\circ} \mathrm{W}$ (X top axis, units: $\otimes /^{\circ}$; color: black). 


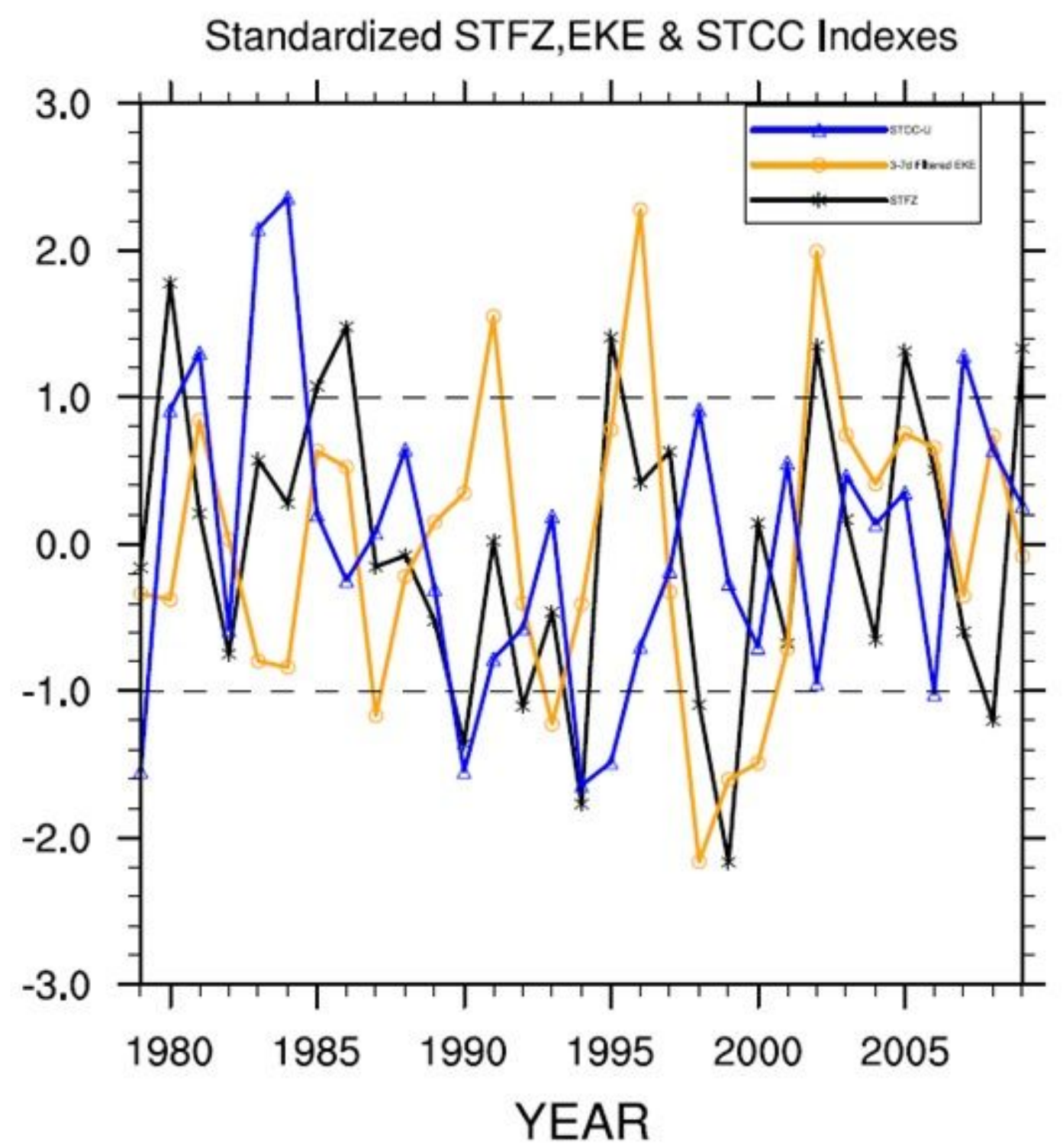

Figure 2

Standardized time series of the ITS (black), EKE (orange) index and U-component of STCC index (blue). The ITS, EKE index, and U-component of STCC index are the spatial average of the SST gradient in $24^{\circ} \mathrm{N}$ $32^{\circ} \mathrm{N} \& 140^{\circ} \mathrm{E}-140^{\circ} \mathrm{W}, 3-7$ days bandpass filtered sea surface EKE in the eddy locations within STFZ, and u-component of current at sea surface in $18^{\circ} \mathrm{N}-24^{\circ} \mathrm{N} \& 140^{\circ} \mathrm{E}-157^{\circ} \mathrm{W}$, respectively. The reference lines are $\pm \sigma$. $X$-axis presents the years; $Y$-axis presents the standardized indexes. 


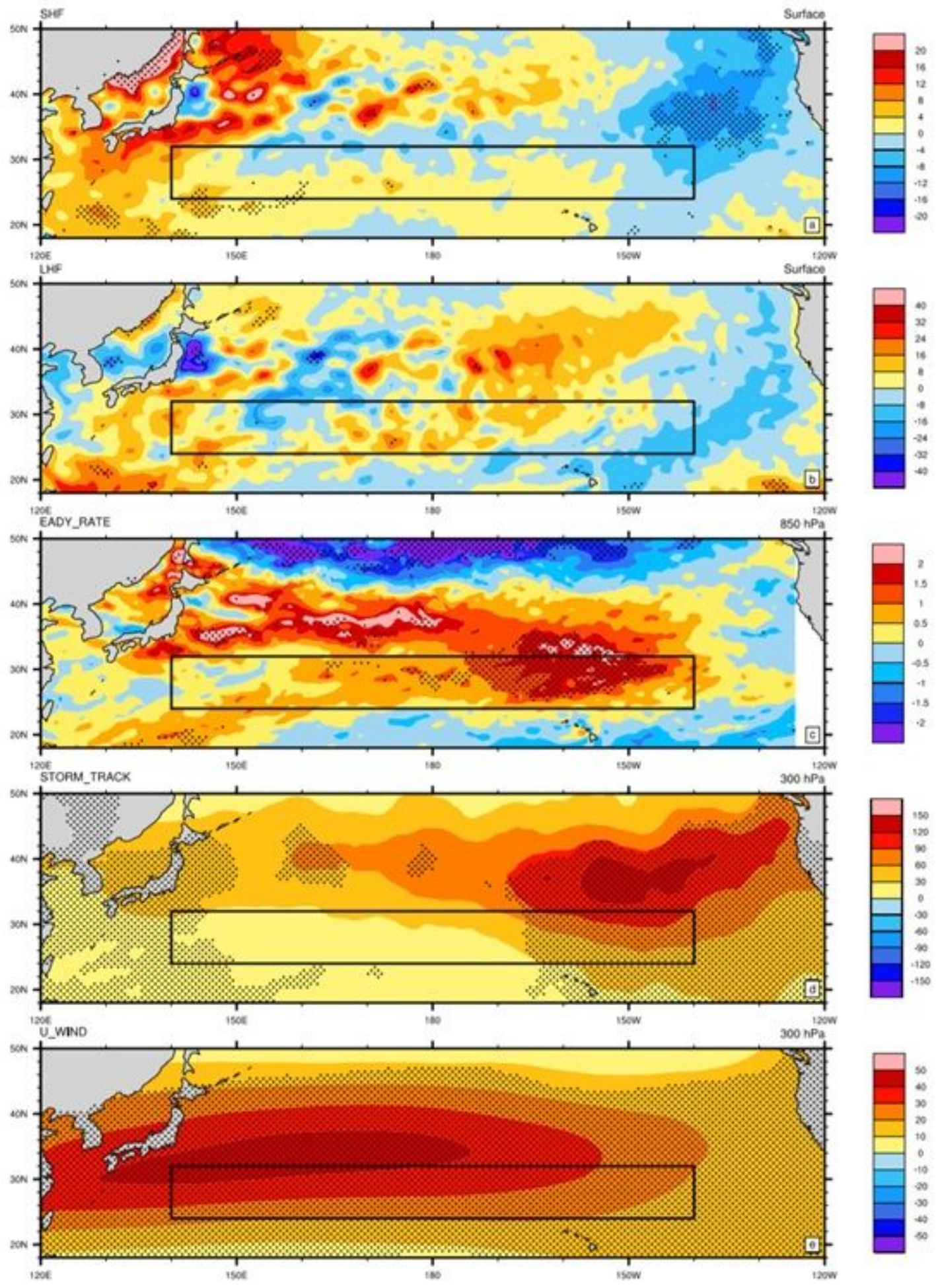

\section{Figure 3}

Difference of averaged (a) SHF (units: W·m-2), (b) LHF (units: W·m-2), (c) Eady growth rate (units: 10$5 \mathrm{~m} \cdot \mathrm{s}-2$ ), (d) storm track at $300 \mathrm{hPa}$ (units: $\mathrm{m} 2 \mathrm{~s}-2$ ), (e) u-component of wind at $300 \mathrm{hPa}$ (units: $\mathrm{m} \cdot \mathrm{s}-1$ ) between stronger and weaker years of the STFZ. The STFZ region is outlined by the black box. Dotted areas have passed $95 \%$ t-test significant level. 


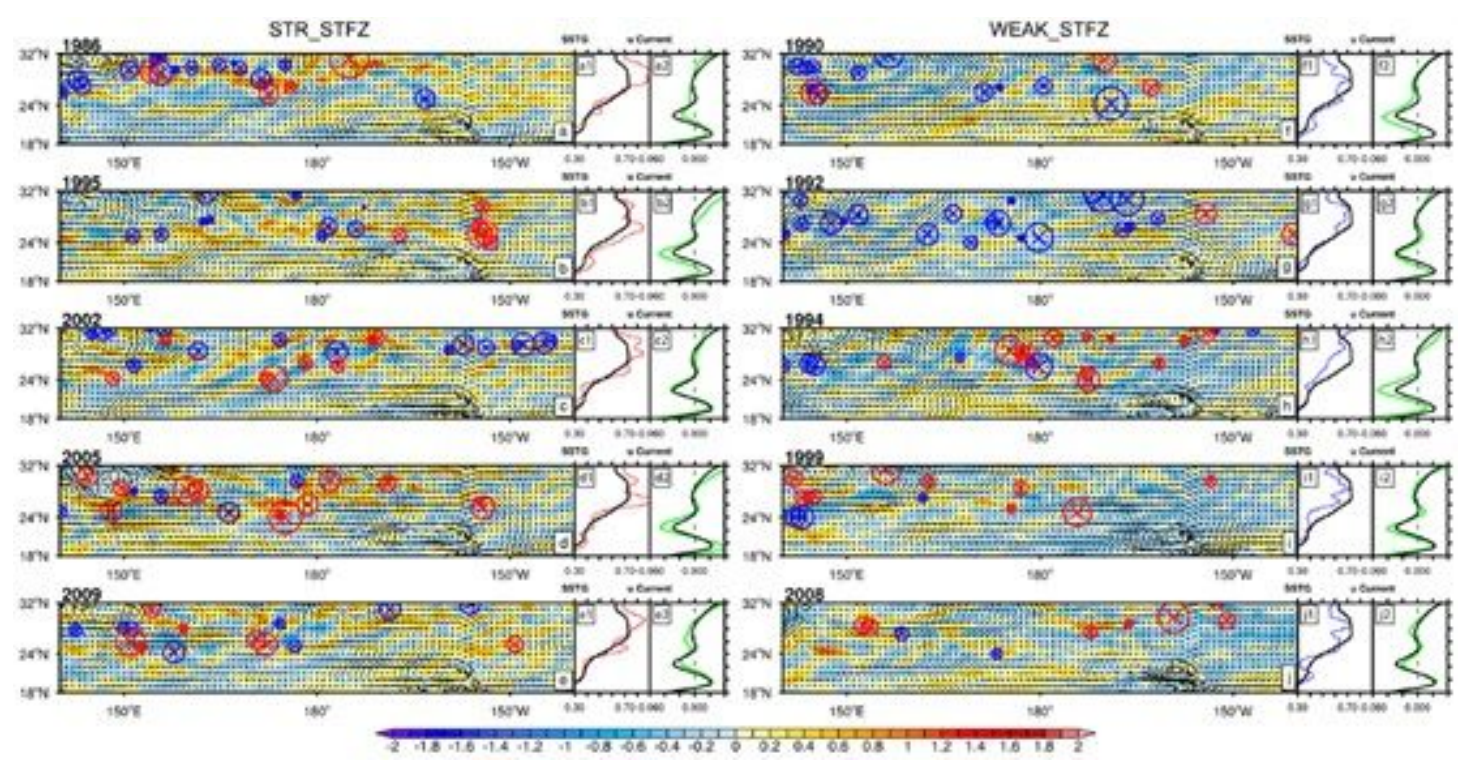

\section{Figure 4}

Comparison of eddy occurrences in stronger (a-e) and weaker (f-j) of STFZ intensity years. Blue (Red) marker represents cyclone (anticyclone) eddies. Meridional SST gradient anomaly (shadings, units: $\otimes /^{\circ}$ ) and averaged current velocity (vectors, units: $m \cdot s-1$ ) from surface to $205 \mathrm{~m}$ of the year are also given in pictures. (a1-j1) present zonal means of meridional SST gradient, black solid line is average from all 31 years, red or blue line is average of the stronger or weaker STFZ year; (a2-j2) present zonal means of current u-component from $140^{\circ} \mathrm{E}$ to $157^{\circ} \mathrm{W}$, black solid line is the average value of all 31 years, green line is the value of the respective year.

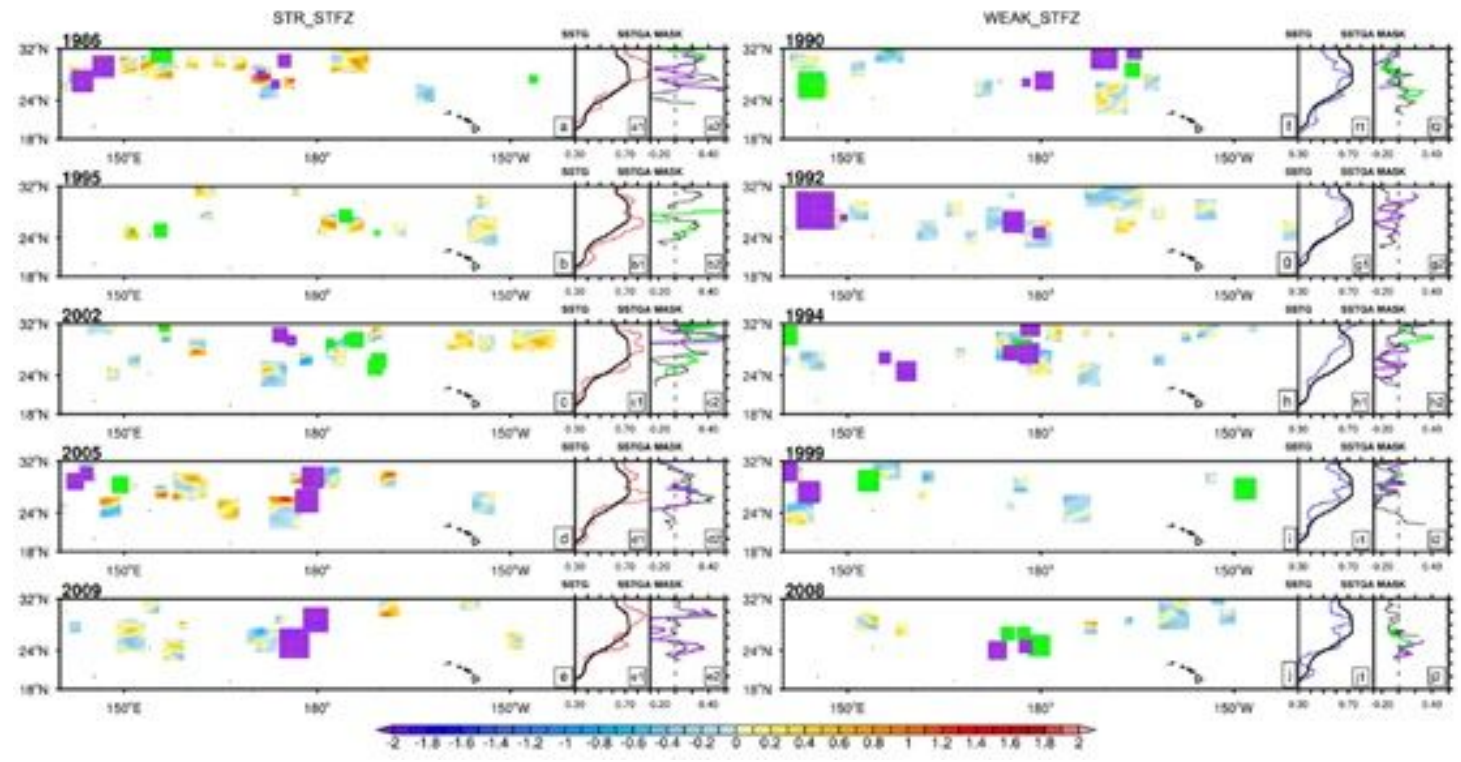

Figure 5

Comparison of eddy occurrence in stronger (a-e) and weaker ( $\mathrm{f}-\mathrm{j})$ years. Meridional SST gradient anomaly (shadings, units: $\nabla /^{\circ}$ ) are masked out in eddy positions. (a1-j1) present zonal means of meridional SST gradient from $140^{\circ} \mathrm{E}$ to $140^{\circ} \mathrm{W}$, black solid line is average from all 31 years, red and blue lines are average 
of the stronger or weaker STFZ year. (a2-j2) present zonal means of meridional SST gradient anomaly caused by the ISO eddies (black), the DBL (green) and the PAIR (purple) eddies. The cell-shading ones are the positions of DBL (green) and PAIR (purple) eddies. The ones with normal shadings are ISO eddies.
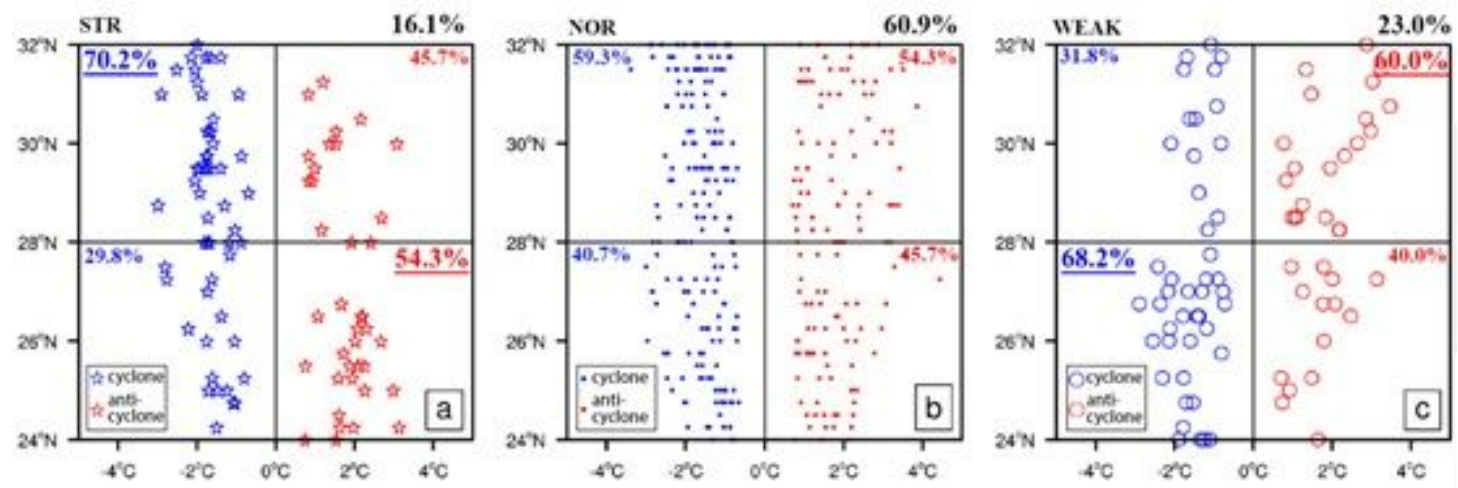

\section{Figure 6}

Spatial distribution and ratio of eddies in (a) stronger, (b) normal, and (c) weaker years of the STFZ. For all eddies in 31 years, $16.1 \%$ eddies occur in stronger STFZ years; $60.9 \%$ and $23.0 \%$ for normal and weaker years, respectively. Obviously, most cyclone eddies occur north (south) to $28^{\circ} \mathrm{N}$ with $70.2 \%$ $(68.2 \%)$ of total cyclones in the stronger (weaker) STFZ intensity years, while anticyclone eddies occur north (south) to $28^{\circ} \mathrm{N}$ with $60.0 \%$ (54.3\%) in the weaker (stronger) years. 

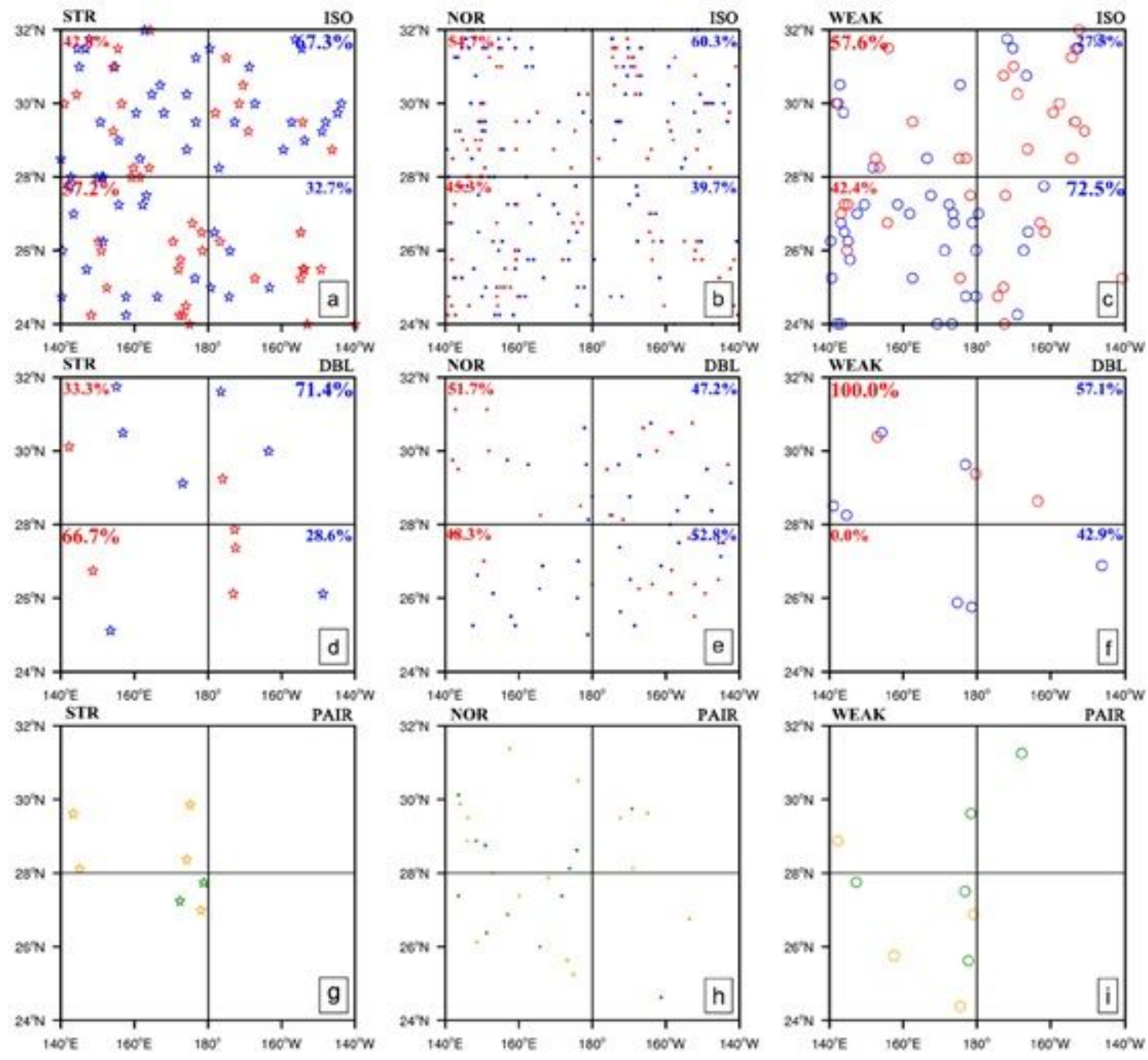

Figure 7

Spatial distribution and ratio of eddies in $(a, d, g)$ stronger, $(b, e, h)$ normal, and $(c, f, i)$ weaker years of the STFZ. (a-c) for ISO, (d-f) for DBL and ( $g-i)$ for PAIR eddies. ISO eddies perform almost the same as that in Fig. 6, and more significant percentage characteristics appear for DBL eddies. For the PAIR eddies, longitudinal cyclone-anticyclone pairs (cold to the north and warm to the south) are presented with orange markers of $(\mathrm{g}-\mathrm{i})$ and longitudinal anticyclone-cyclone pairs (warm to the north and cold to the south) are presented with green markers of $(\mathrm{g}-\mathrm{i})$. 

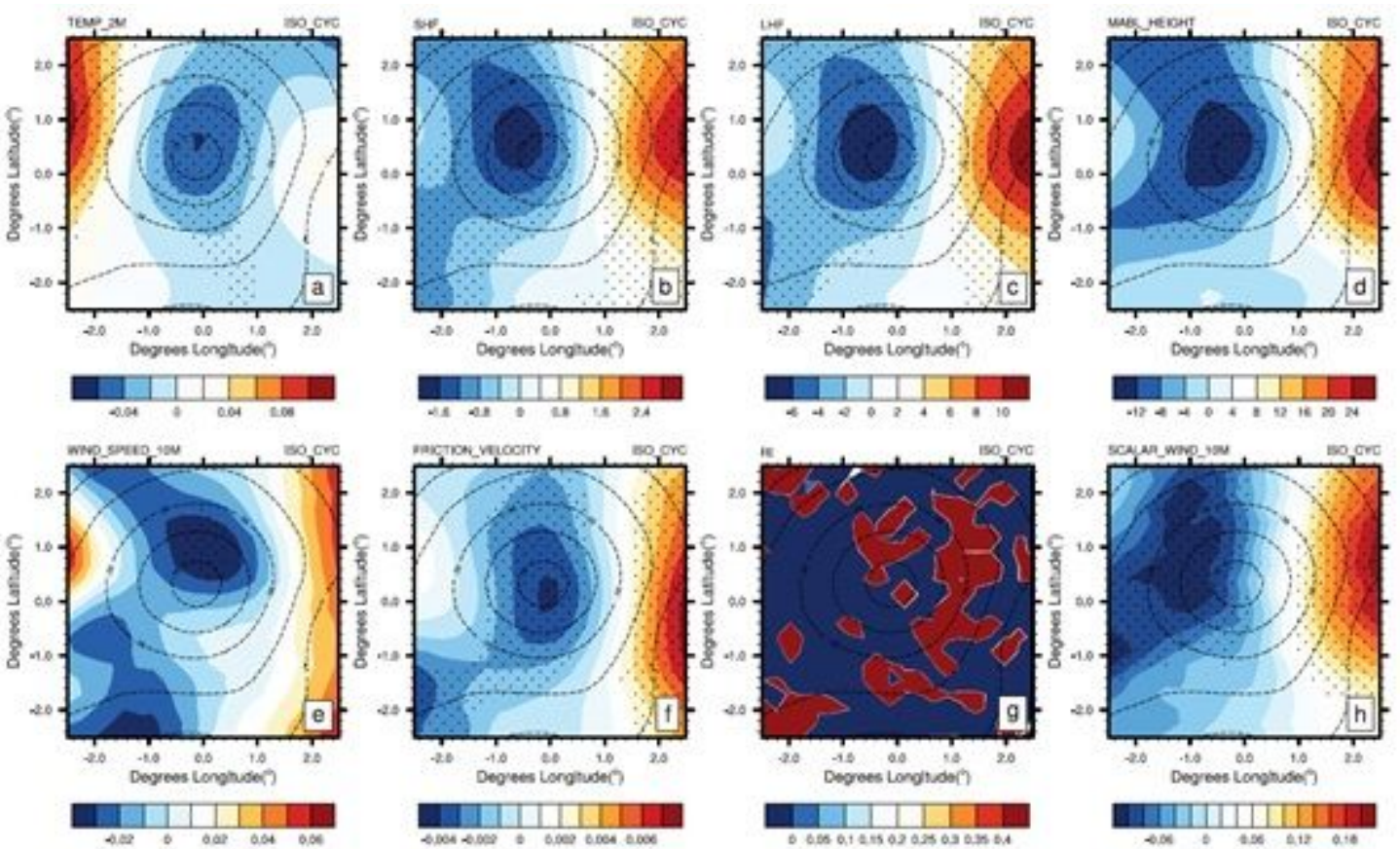

Figure 8

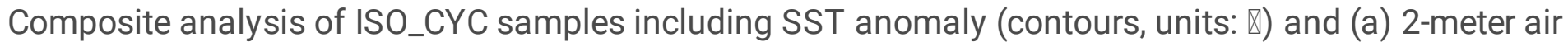

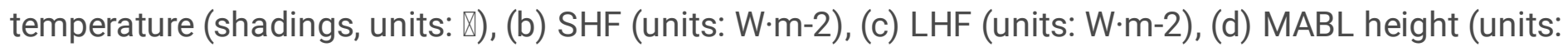
m), (e) 10-meter wind speed (units: $m \cdot s-1$ ), (f) surface frictional velocity (units: $m \cdot s-1$ ), (h) 10-meter scalar wind (units: $\mathrm{m} \cdot \mathrm{s}-1$ ) anomalies and $(\mathrm{g})$ the gradient Richardson number at $950 \mathrm{hPa}$. Dotted areas have passed $95 \%$ t-test significant level.
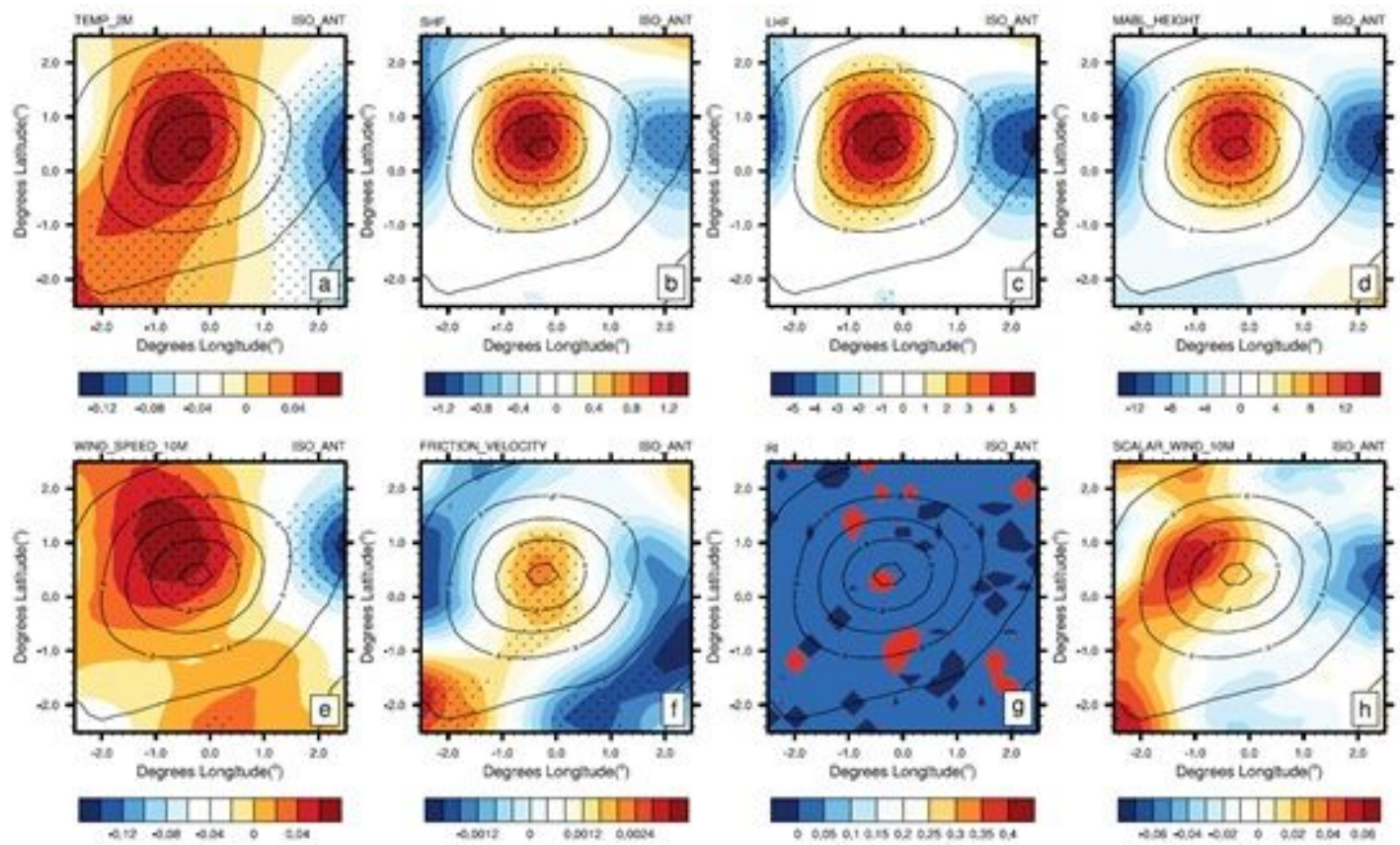

Figure 9 
Composite analysis of ISO_ANT samples including SST anomaly (contour, units: $₫$ ) and (a) 2-meter air

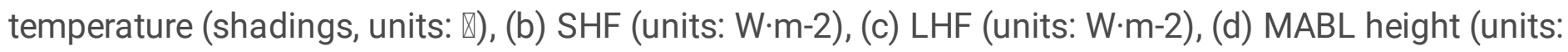
m), (e) 10-meter wind speed (units: $m \cdot s-1$ ), (f) surface frictional velocity (units: $m \cdot s-1$ ), (h) 10-meter scalar wind (units: $\mathrm{m} \cdot \mathrm{s}-1$ ) anomalies and $(\mathrm{g})$ the gradient Richardson number at $950 \mathrm{hPa}$. Dotted areas have passed $95 \%$ t-test significant level.
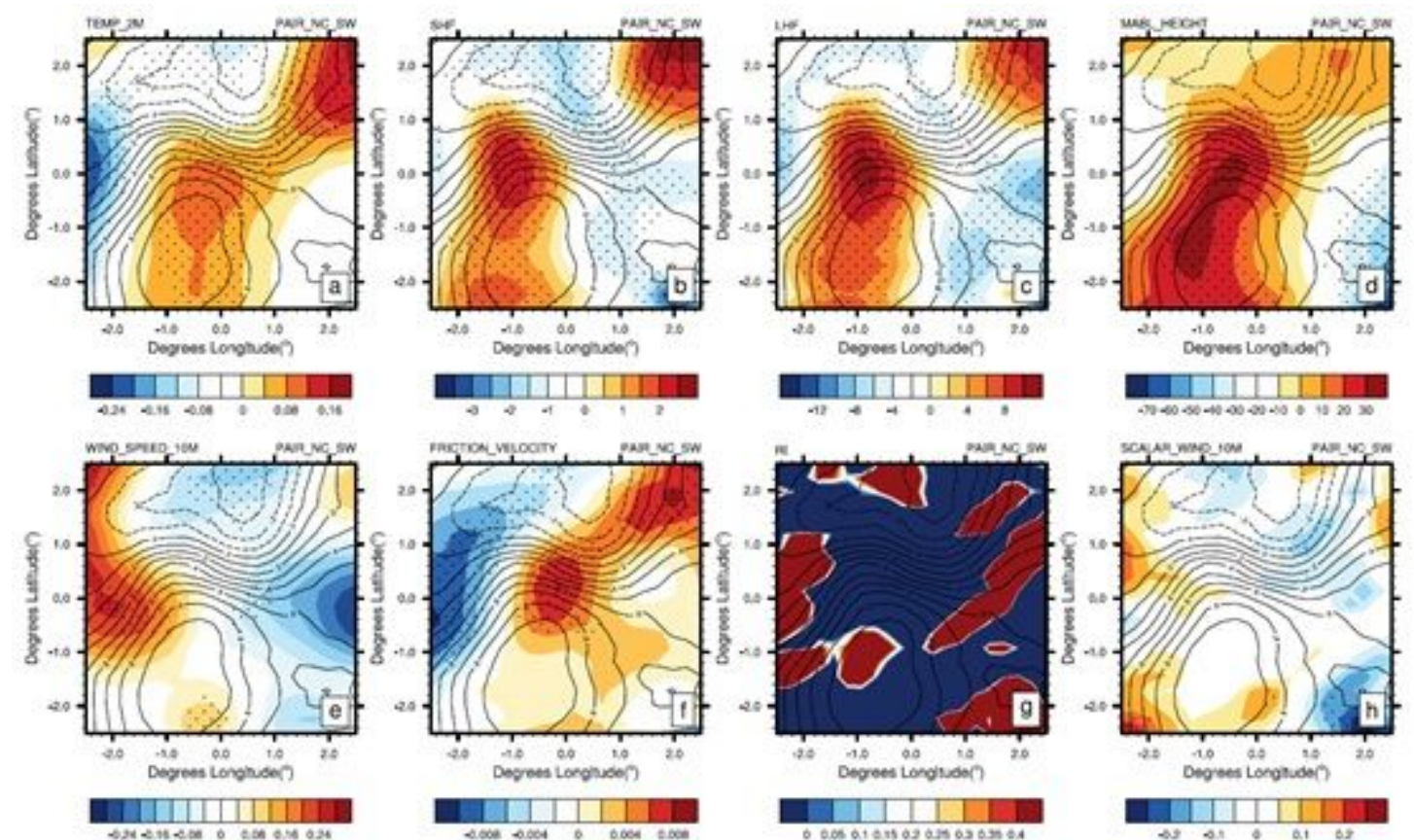

\section{Figure 10}

Composite analysis of PAIR_NC_SW samples including SST anomaly (contours, units: $₫$ ) and (a) 2-meter

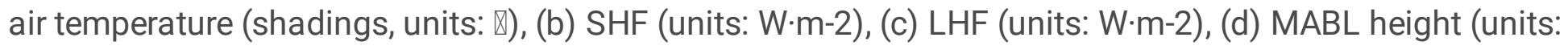
m), (e) 10-meter wind speed (units: $m \cdot s-1$ ), (f) surface frictional velocity (units: $m \cdot s-1$ ), (h) 10-meter scalar wind (units: $\mathrm{m} \cdot \mathrm{s}-1$ ) anomalies and (g) the gradient Richardson number at $950 \mathrm{hPa}$. Dotted areas have passed $95 \%$ t-test significant level. 

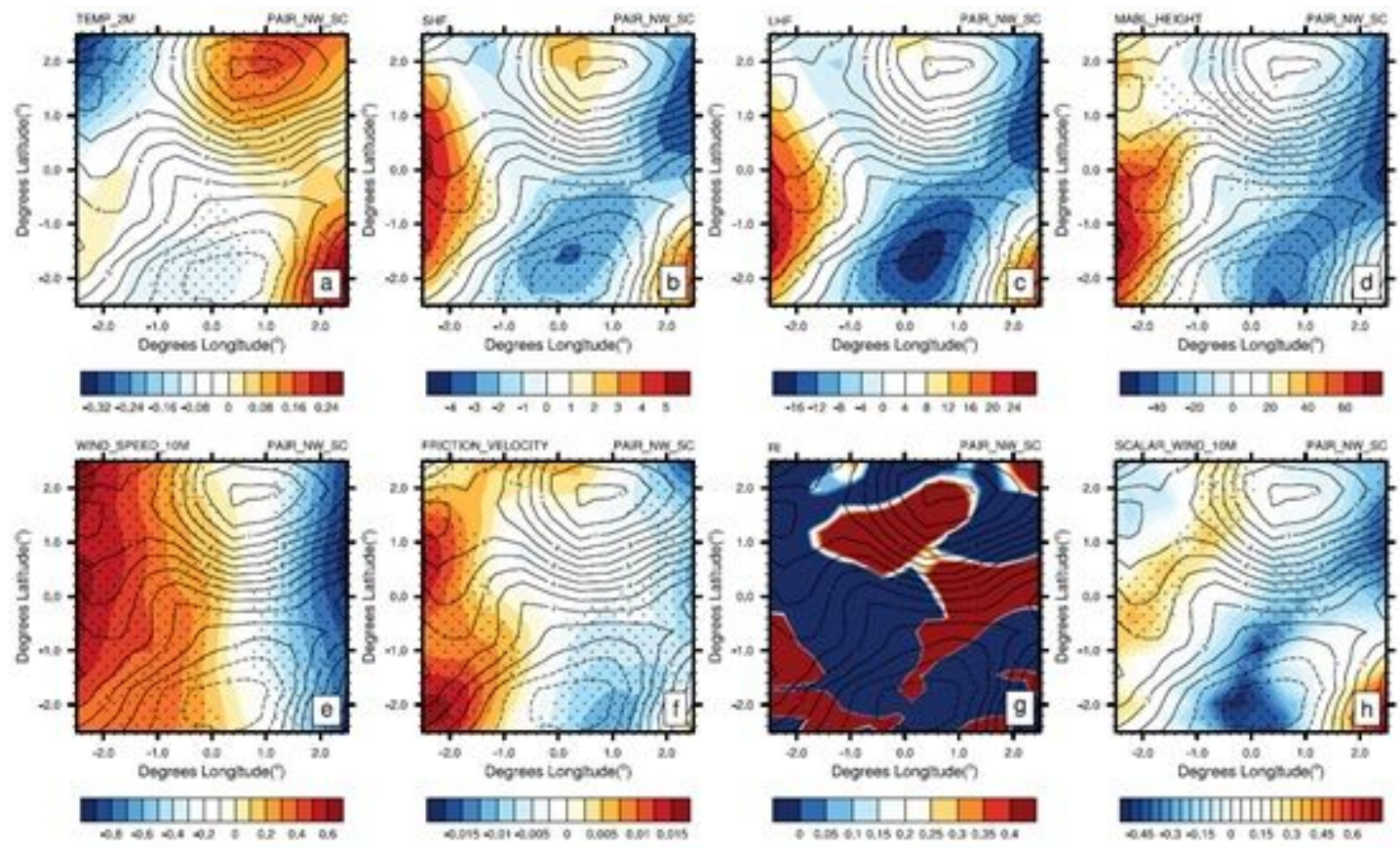

\section{Figure 11}

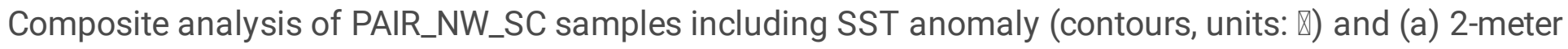

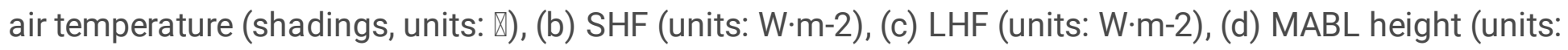
m), (e) 10-meter wind speed (units: $m \cdot s-1$ ), (f) surface frictional velocity (units: m·s-1), (h) 10-meter scalar wind (units: $\mathrm{m} \cdot \mathrm{s}-1$ ) anomalies and (g) the gradient Richardson number at $950 \mathrm{hPa}$. Dotted areas have passed $95 \%$ t-test significant level. 

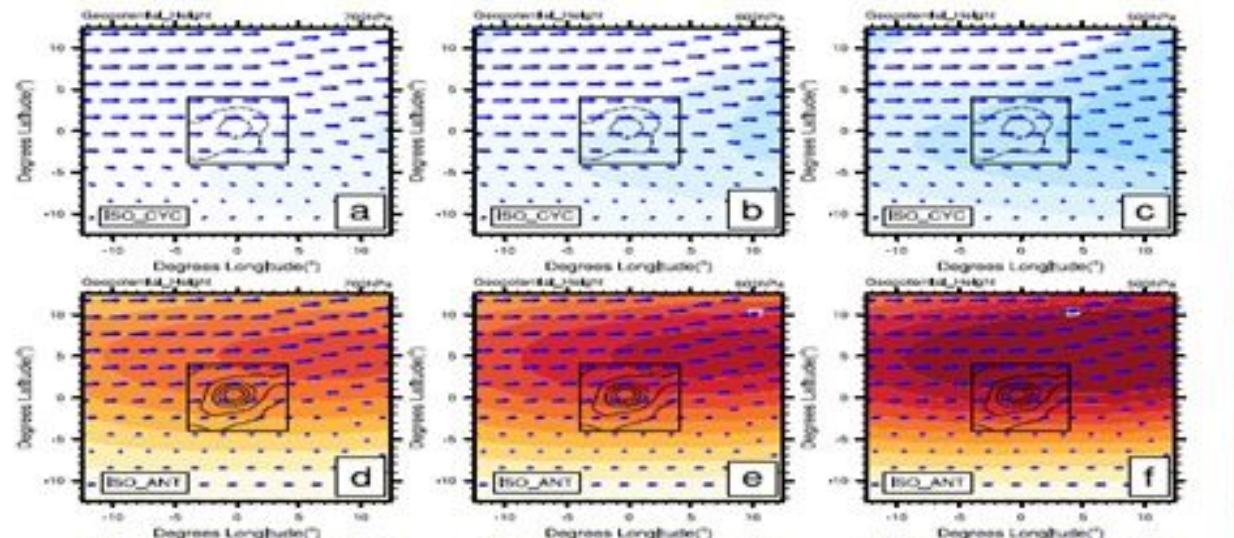

45

40

35

30
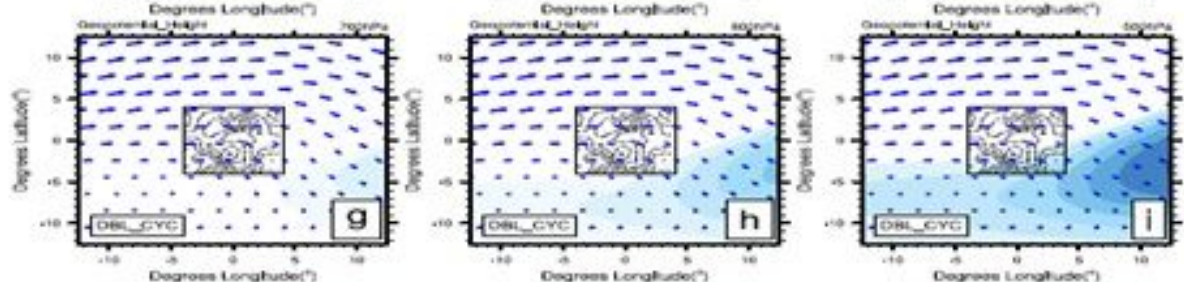

25
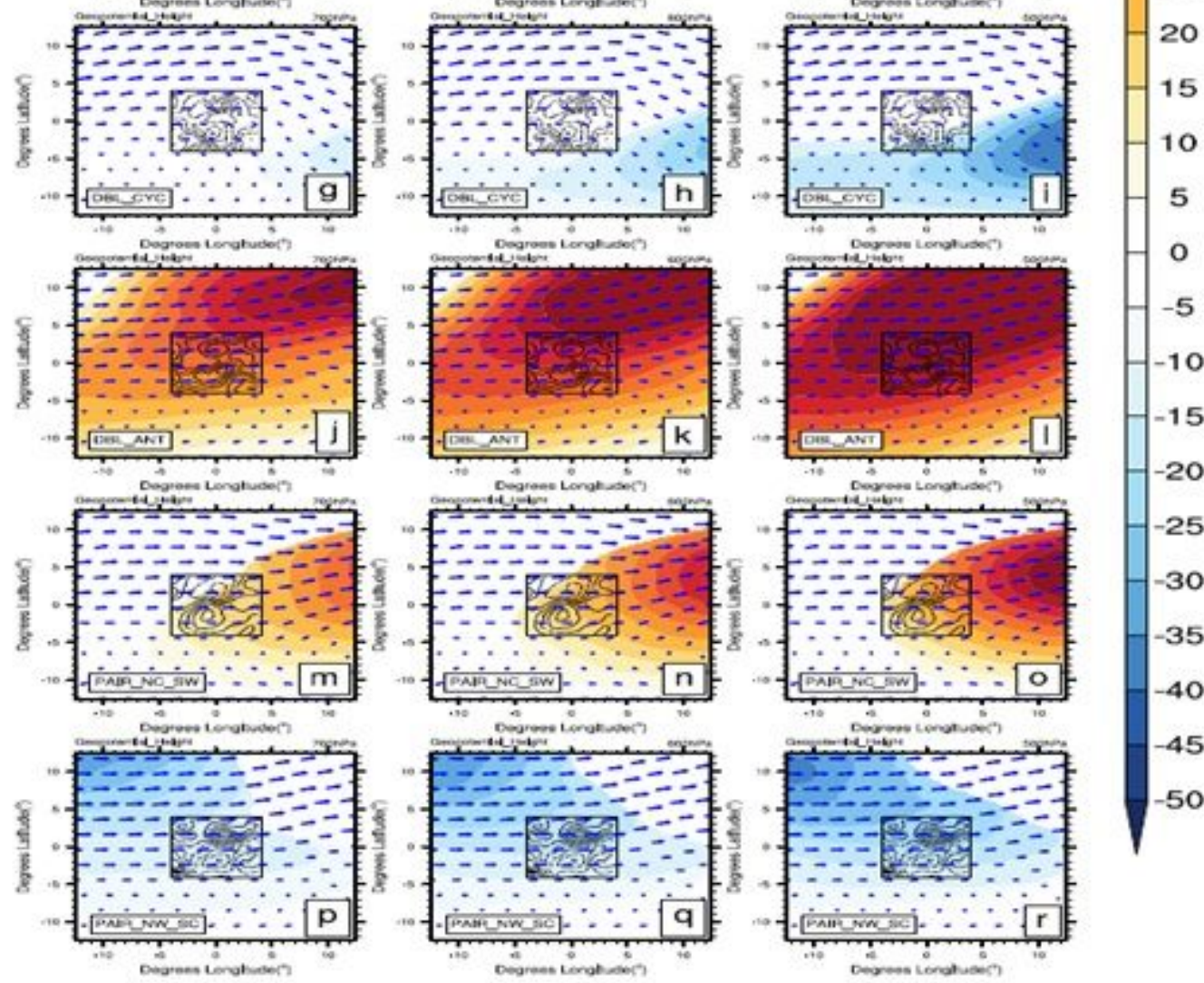

10

5
0
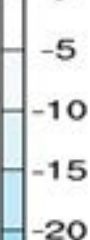

-20
-25

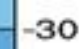

$-35$

$-40$

$-45$

$-50$

Figure 12

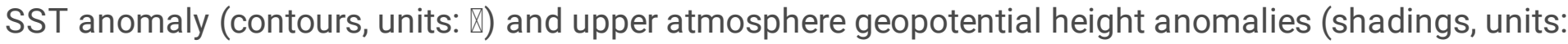
$\mathrm{m}$, passed 95\% t-test significant level) in composite analysis of (a-c) ISO_CYC (d-f) ISO_ANT (g-i) DBL_CYC (j-I) DBL_ANT (m-o) PAIR_NC_SW (p-r) PAIR_NW_SC at $700 \mathrm{hPa}, 600 \mathrm{hPa}$ and $500 \mathrm{hPa}$. Vectors present wind field interpolated to MABL top. 

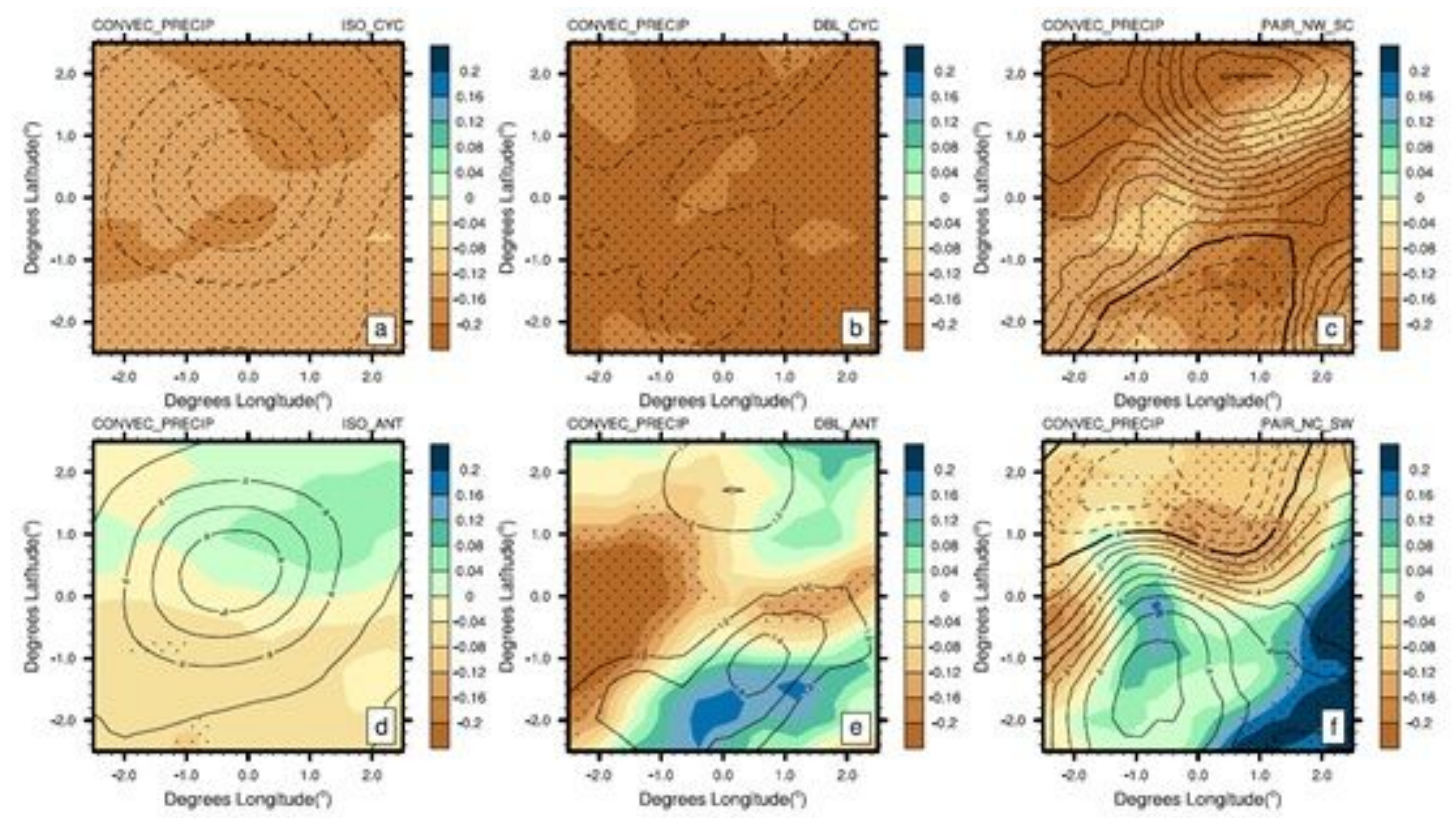

Figure 13

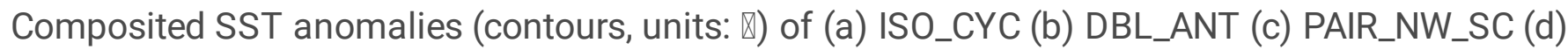
ISO_ANT (e) DBL_ANT (f) PAIR_NC_SW and composited anomalies (shadings, units: $\mathrm{kg} \cdot \mathrm{m}-2$ ) of convective precipitation. Dotted areas have passed $95 \% \mathrm{t}$-test significant level.

(b) Remote forcing effects

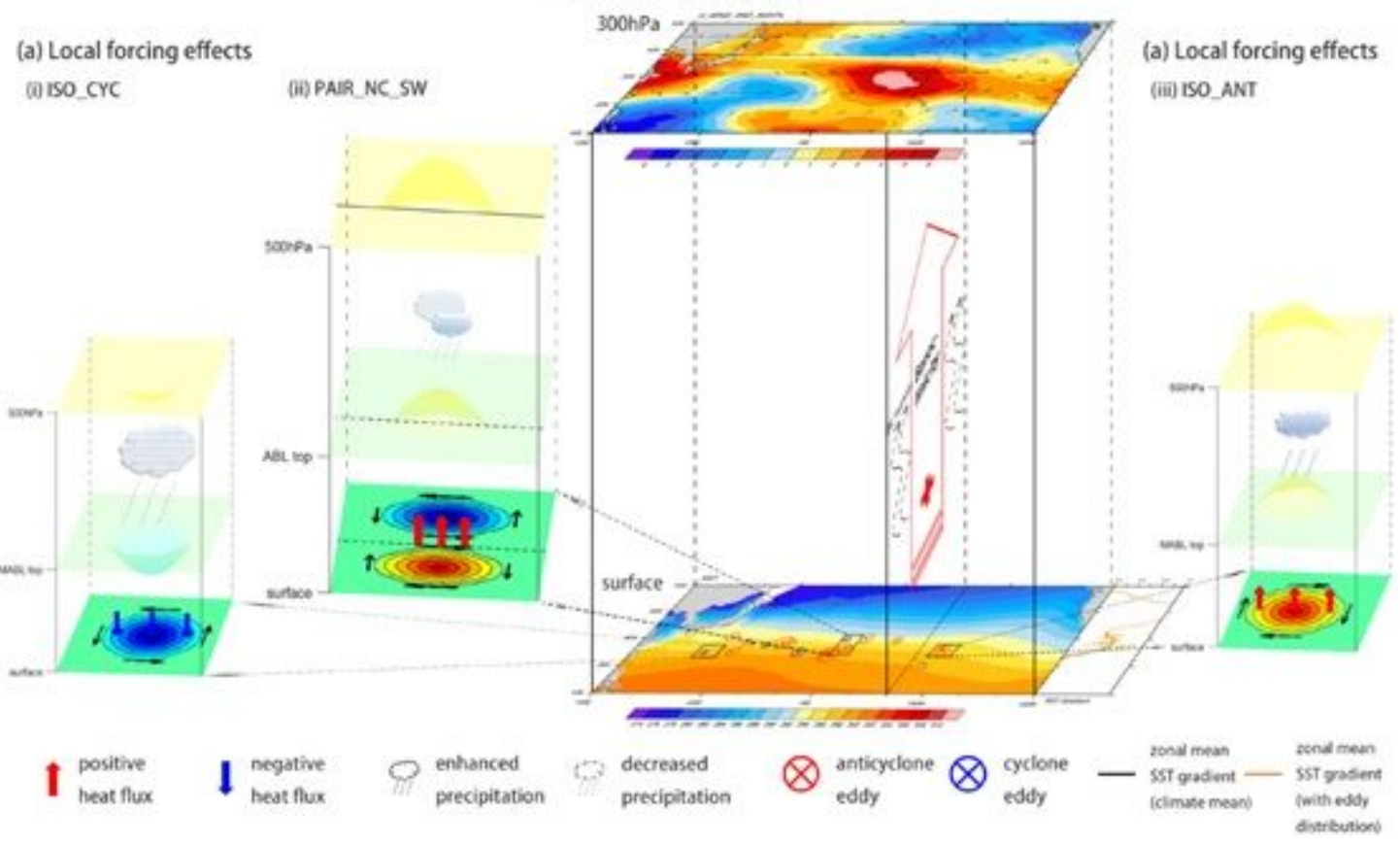

Figure 14

Schematic depiction of the (a) local and (b) remote forcing of oceanic eddies on atmosphere in the STFZ during winter. (a) surface layer presents SST anomaly and heat flux induced by eddies, responding geopotential heights are presented by the bulge of each face, and enhanced/decreased precipitation are 
given as icons; (b) a certain kind of eddy distribution overlays climatic SST, strengthening the STFZ intensity and affecting wind at $300 \mathrm{hPa}$.

\section{Supplementary Files}

This is a list of supplementary files associated with this preprint. Click to download.

- SupplementarymeterialstoCD.docx 